\title{
Phosphocreatine Levels in the Left Thalamus Decline during Wakefulness and Increase after a Nap
}

\author{
Ali Gordji-Nejad, ${ }^{1}$ Andreas Matusch, ${ }^{1}$ Shumei Li, ${ }^{1}$ Tina Kroll, ${ }^{1}$ Simone Beer, ${ }^{1}$ David Elmenhorst, ${ }^{1,2}$ and Andreas Bauer ${ }^{1,3}$ \\ ${ }^{1}$ Institute of Neuroscience and Medicine, Forschungszentrum Jülich, 52425 Jülich, Germany, ${ }^{2}$ Department of Psychiatry and Psychotherapy, Rheinische \\ Friedrich-Wilhelms-University Bonn, 53127 Bonn, Germany, and ${ }^{3}$ Department of Neurology, Medical Faculty, Heinrich Heine University Düsseldorf, 40225 \\ Düsseldorf, Germany
}

Scientists have hypothesized that the availability of phosphocreatine (PCr) and its ratio to inorganic phosphate (Pi) in cerebral tissue form a substrate of wakefulness. It follows then, according to this hypothesis, that the exhaustion of PCr and the decline in the ratio of PCr to Pi form a substrate of fatigue. We used ${ }^{31} \mathrm{P}$-magnetic resonance spectroscopy $\left({ }^{31} \mathrm{P}\right.$-MRS) to investigate quantitative levels of PCr, the $\gamma$-signal of ATP, and Pi in 30 healthy humans (18 female) in the morning, in the afternoon, and while napping $(n=15)$ versus awake controls $(n=10)$. Levels of PCr $(2.40 \mathrm{mM}$ at 9 A.M. $)$ decreased by $7.0 \pm 0.8 \%\left(p=7.1 \times 10^{-6}, t=-5.5\right)$ in the left thalamus between 9 A.M. and 5 P.M. Inversely, $\mathrm{Pi}(0.74 \mathrm{mM}$ at 9 A.M. $)$ increased by $17.1 \pm 5 \%(p=0.005, t=3.1)$ and pH levels dropped by $0.14 \pm 0.07(p=$ $0.002 ; t=3.6$ ). Following a $20 \mathrm{~min}$ nap after 5 P.M., local PCr, Pi, and pH were restored to morning levels. We did not find respective significant changes in the contralateral thalamus or in other investigated brain regions. Left hemispheric PCr was signficantly lower than right hemispheric PCr only at 5 P.M. in the thalamus and at all conditions in the temporal region. Thus, cerebral daytime-related and sleep-related molecular changes are accessible in vivo. Prominent changes were identified in the thalamus. This region is heavily relied on for a series of energy-consuming tasks, such as the relay of sensory information to the cortex. Furthermore, our data confirm that lateralization of brain function is regionally dynamic and includes PCr.

Key words: ${ }^{31} \mathrm{P}$ magnetic resonance spectroscopy; inorganic phosphate; $\mathrm{pH}$; phosphocreatine; thalamus

\section{Significance Statement}

The metabolites phosphocreatine (PCr) and inorganic phosphate (Pi) are assumed to inversely reflect the cellular energy load. This study detected a diurnal decrease of intracellular PCr and a nap-associated reincrease in the left thalamus. Pi behaved inversely. This outcome corroborates the role of the thalamus as a region of high energy consumption in agreement with its function as a gateway that relays and modulates information flow. Conversely to the dynamic lateralization of thalamic PCr, a constantly significant lateralization was observed in other regions. Increasing fatigue over the course of the day may also be a matter of cerebral energy supply. Comparatively fast restoration of that supply may be part of the biological basis for the recreational value of "power napping."

\section{Introduction}

Many recent studies have focused on the diurnal alterations of cerebral energy supply. Modalities such as PET, MRI, EEG, and behavioral tests have provided a wide spectrum of parameters to characterize different states of wakefulness and sleep propensity.

\footnotetext{
Received April 4, 2018; revised Sept. 19, 2018; accepted Sept. 25, 2018.

Author contributions: A.G.-N. and A.B. designed research; A.G.-N., A.M., S.L., T.K., and D.E. performed research; A.G.-N., S.L., and S.B. analyzed data; A.G.-N., A.M., and A.B. wrote the paper.

This work was supported by by Forschungszentrum Jülich. Investigations were performed at the laboratories of Forschungszentrum Jülich.

The authors declare no competing financial interests.

Correspondence should be addressed to Dr. Ali Gordji-Nejad, Institute of Neuroscience and Medicine (INM-2), Forschungszentrum Jülich, 52425 Jülich, Germany. E-mail: a.gordjinejad@fz-juelich.de.

https://doi.org/10.1523/JNEUROSCI.0865-18.2018

Copyright $\odot 2018$ the authors $\quad 0270-6474 / 18 / 3810552-14 \$ 15.00 / 0$
}

Diurnal exhaustion of cerebral energy and activational reserves has been proposed as a factor contributing to fatigue in the evening (Porkka-Heiskanen and Kalinchuk, 2011). Dijk and coworkers (1987) let volunteers nap for $30 \mathrm{~min}$ after being awake for $10,12,14,16,18$, or $20 \mathrm{~h}$, respectively. The reseachers recorded $90 \%$ of night sleep maximum slow-wave activity at $16 \mathrm{~h}$ and later. Using fMRI (Marek et al., 2010), subjects performing a Stroop task were investigated after being awake for 6, 10, 14, 18, and $22 \mathrm{~h}$. The researchers found maximal network activation at $6 \mathrm{~h}$ and minimal at $18 \mathrm{~h}$. Glucose metabolism $\left(\mathrm{CMR}_{\mathrm{Glc}}\right)$ was studied using $\left[{ }^{18} \mathrm{~F}\right] \mathrm{FDG}-\mathrm{PET}$, perfusion was studied using fMRI or $\left[{ }^{15} \mathrm{O}\right] \mathrm{H}_{2} \mathrm{O}$-PET, and oxygen consumption $\left(\mathrm{CMR}_{\mathrm{Ox}}\right)$ was studied using $\left[{ }^{15} \mathrm{O}\right] \mathrm{O}_{2}$-PET. Two studies investigating subjects in the morning and in the afternoon revealed a global decrease of abso- 
lute $\mathrm{CMR}_{\mathrm{Glc}}$ by 6 and 4\% (Buysse et al., 2004; Shannon et al., 2013). While the decrease was pronounced in cortical areas, both detected constant $\mathrm{CMR}_{\mathrm{Glc}}$ in the thalamus. $\mathrm{CMR}_{\mathrm{Ox}}$ decreased globally by $5 \%$ and a constant oxygen-glucose index pointed to minimal admixture of anaerobic glycolysis (Shannon et al., 2013).

Plante et al. (2014) reported ${ }^{31} \mathrm{P}$ magnetic resonance spectroscopy (MRS) in $8.8 \mathrm{ml}$ voxels of eight subjects showing a significant increase of PCr but not of ATP after recovery sleep following sleep deprivation in gray matter but not in white matter. Baseline condition versus sleep deprivation did not differ significantly. The metabolic Pi/PCr ratio was constant through all conditions. The same group (Trksak et al., 2013) previously reported $<3 \%$ change in global PCr and ATP during baseline, sleep deprivation, and recovery sleep in 14 controls, including the eight subjects above. Changes of other metabolites after sleep deprivation were detected by ${ }^{1} \mathrm{H}$-MRS (Urrila et al., 2006).

Ex vivo measurements of ATP and PCr in brain extracts from rats before and after $3 \mathrm{~h}$ of sleep deprivation showed a decrease of PCr by $57 \%$ and of ATP by $40 \%$ in the frontal cortex (Dworak et al., 2010, 2017).

As neuronal firing is the major energy consumer in the brain, states with prevailing slow EEG activity may be associated with lower energy demand. In some neurons, firing rates were even reduced to silence during delta sleep (Nir et al., 2011). This is consistent with the results of $\left[{ }^{18} \mathrm{~F}\right] \mathrm{FDG}$-PET studies before and after $32 \mathrm{~h}$ total sleep deprivation. Considerable reductions of absolute $\mathrm{CMR}_{\mathrm{Glc}}$ after sleep deprivation were observed in thalamus (left: $-23 \%$; right: $-18 \%$ ), basal ganglia, and cerebellum; a moderate decline was detected in lateral frontal $(-9 \%)$ and temporal cortices $(-13 \%$; Wu et al., 1991, 2006). The thalamus, a pivotal hub of somatic and cortical afferences and efferences, is particularly active during wakefulness. During sleep it is known as the generator of EEG spindles (McCormick, 2002; Lüthi, 2014). Therefore, it was included as a candidate region.

In research concerning diurnal and nocturnal changes of brain lateralization, Casagrande and Bertini (2008), using a simple finger-tapping motor paradigm, observed a switch of left to right hemispheric dominance. Falling asleep and waking up were differently delayed in different brain regions in long-term EEG studies and occurred earlier in the left hemisphere (Rial et al., 2013). Some authors addressed the correlation of lateralization of different tasks and brain regions by fMRI. Indeed, all were found correlated, except parietal activity related to spatial attention (Badzakova-Trajkov et al., 2010).

Given that so little data are available on the fate of high-energy phosphates in the human brain during daytime, we designed a study using ${ }^{31} \mathrm{P}$ MRS. To detect changes of PCr, Pi, and $\gamma$-ATP signals, we used a longitudinal study design that included measurements in the morning, in the afternoon, and during a short nap.

\section{Materials and Methods}

Participants. The study included 32 healthy subjects (19 females, 13 males; mean age, $36 \pm 3$ years; range, $20-61$ years) recruited from scientific staff and by local advertisements. Medical histories were free of sleep, psychiatric, neurological, alcohol, or drug disorders. One male was excluded due to movement artifacts and one female due to lefthandedness. All 30 remaining subjects were right-handed nonsmokers who took no medications. Handedness was assessed using a 19-item adaption of the Edinburgh Handedness Inventory (Oldfield, 1971) and revealed scores at $16.2 \pm 1.1$ of a maximum of 19 . Subjects slept $\geq 7 \mathrm{~h}$ on the night before the study. Most of the participants were members of the scientific staff. Between the morning and the afternoon sessions, all subjects performed their usual work in a scientific research center, which was mainly office work using computers and thus highly demanding on left- hemispheric capacities. During this time, all avoided caffeine. The study was in accordance with the Declaration of Helsinki and approved by the ethics committee of the medical faculty of the University of Düsseldorf.

Measurement procedure. A 3.0 T Magnetom scanner (TrioTim, Siemens) was equipped with a double-tuned ${ }^{31} \mathrm{P}-{ }^{1} \mathrm{H}$ head coil from Rapid Biomedical. MRS protocols of 20 min were identical throughout all subjects and conditions. Subjects were measured in two sessions, one starting at 9:04 A.M. ( $\pm 26 \mathrm{~min})$ and one at 4:52 P.M. ( $\pm 19 \mathrm{~min}$; Fig. $1 \mathrm{~A})$. The morning session included one MRS scan of 20 min awake (9 A.M., $n=$ 30,18 female). The afternoon session included one MRS scan of $20 \mathrm{~min}$ awake (5 P.M., $n=30,18$ female) and two subsequent MRS scans of 20 min, either while napping (Nap1, $n=15,8$ female; Nap2, $n=13,7$ female) or awake (Wake1, Wake2, $n=10$ controls, 7 female). During the scans in the wake-state, subjects were requested to stay awake and keep their eyes open. All subjects were equipped with a pulse oximeter, permanently monitored, and occasionally reminded to keep their eyes open. After completion of the afternoon wake scan, members of the nap subcohort was allowed to close their eyes and fall asleep. Napping state was defined by rest of voluntary movements, clear slowing of breathing, and a drop of the heart rate by $\geq 5 / \mathrm{min}$ and reached after an average delay of $7 \pm 3 \mathrm{~min}$ after the end of the wake scan. The average individual drop in heart rate to sleep stages 1 and 2 was reported at $4.1 / \mathrm{min}$ and $6.64 /$ $\min$ (Burgess et al., 1999) and at 2.5/min and 5.8/min (Zemaityte et al., 1986; Burgess et al., 1999), respectively. None of the subjects spontaneously awakened during or between the Nap1 and Nap2 scans and all required vigorous wake-up calls after the end of the procedure.

The thalamus region was positioned in the isocenter of the scanner and in the center of the predefined $8 \times 8$ voxel chemical shift imaging (CSI) grid (Fig. $1 C, D$ ). Furthermore, the grid was centered midsagittally in the $x$-axis and tilted parallel to the anterior commissure-posterior commissure line in the sagittal $(y z)$ plane and shifted with the lower edge crossing the colliculus inferior. An AAH Scout was applied. This coregistration tool enable to perfectly reposition the acquisition grid as in a precedent measurement. Anatomical reference images in the sagittal, coronal, and transversal planes were acquired using $\mathrm{T}_{1}$-weighted twodimensional (2D) flash sequences before the $2 \mathrm{D}$ CSI ${ }^{31} \mathrm{P}-\mathrm{MRS}$ sequences. Manual shimming ensured FWHM $\leq 25 \mathrm{~Hz}$ before data acquisition. Finally, a three-dimensional (3D) MPRAGE sequence used an eightchannel ${ }^{1} \mathrm{H}$-coil (3 T head matrix). All parameters were kept constant throughout all in vivo and phantom measurements.

To test reproducibility, two subjects underwent the entire protocol twice on 2 different days. To exclude any left-right asymmetry of the instrumentation, one subject was scanned in prone and in supine positions at either condition.

Sequences. The $\mathrm{T}_{1}$-weighted $2 \mathrm{D}$ flash sequence used the following parameters: field of view (FOV), $20.2 \times 20.2 \mathrm{~cm}$; voxel size, $0.9 \times 0.7 \times 4$ $\mathrm{mm}^{3}$; slices, 35 ; echo time $(\mathrm{TE})=2.46 \mathrm{~ms}$; repetition time $(\mathrm{TR})=250$ $\mathrm{ms}$; averages, 1 ; acquisition time $(\mathrm{TA})=1.25 \mathrm{~min}$; flip angle, $70^{\circ}$; bandwidth (BW), $330 \mathrm{~Hz} / \mathrm{Px}$; base resolution, 320 .

${ }^{31} \mathrm{P}$ MRS used a $2 \mathrm{D}$-CSI sequence with a $8 \times 8$ voxel isotropic matrix (voxel size, $25 \times 25 \times 25 \mathrm{~mm}^{3}$ ) and the following parameters: FOV, $20 \times$ $20 \mathrm{~cm} ; \mathrm{TE}=2.3 \mathrm{~ms}$; $\mathrm{TR}=3000 \mathrm{~ms}$; averages, $45 ; \mathrm{TA}=20.15 \mathrm{~min}$; tip angle, $90^{\circ}$, complex points, 1.024 ; $\mathrm{BW}, 2 \mathrm{kHz}$.

The MPRAGE sequence used the following parameters: FOV, $25.6 \times$ $25.6 \mathrm{~cm}$; TE $=3.37 \mathrm{~ms}$; TR $=1900 \mathrm{~ms}$; averages, 1 ; $\mathrm{TA}=3.55 \mathrm{~min}$; $\mathrm{TI}=$ $900 \mathrm{~ms}$; flip angle, $9^{\circ}$; BW, $200 \mathrm{~Hz} / \mathrm{Px}$; in-plane matrix size, $256 \times 256$; voxel size, $1 \times 1 \times 1 \mathrm{~mm}^{3}$; parallel imaging technique mode, generalized autocalibrating partially parallel acquisition.

Segmentation. Three-dimensional MPRAGE datasets $\left(1 \mathrm{~mm}^{3}\right)$ were segmented using SPM12 (statistical parametric mapping, The Welcome Trust Centre for Neuroimaging, https://www.fil.ion.ucl.ac.uk/spm/). A fixed set of cubic $8 \times 8(25 \mathrm{~mm})^{3}$ volumes of interest identical to the CSI grid was created with Pmod 3.2.1 (Pmod) and the individual raw MPRAGE datasets were manually coregistered to the grid position at the $2 \mathrm{D}$ flash images. The same affine transformation was applied to the binary segment masks created by SPM and the respective fraction occupied by gray matter, white matter, and CSF was read out.

Quantification. Phantoms were prepared that matched in vivo conditions in the brain tissue. Since each ${ }^{31} \mathrm{P}$ compound has distinct physical 
A

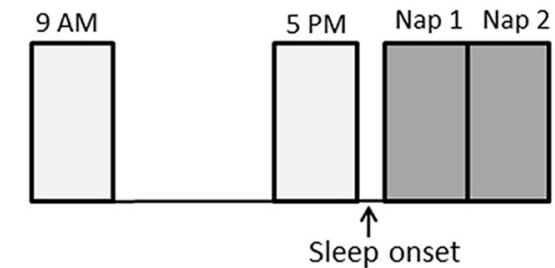

Control

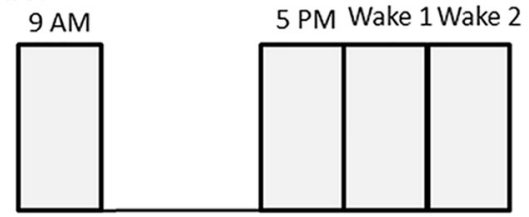

B

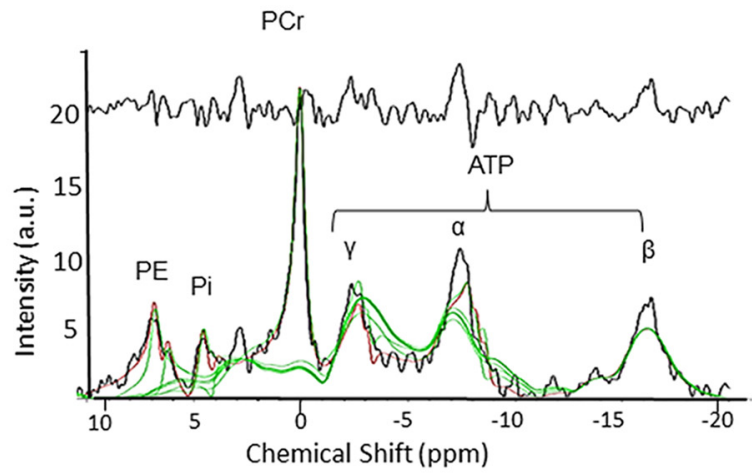

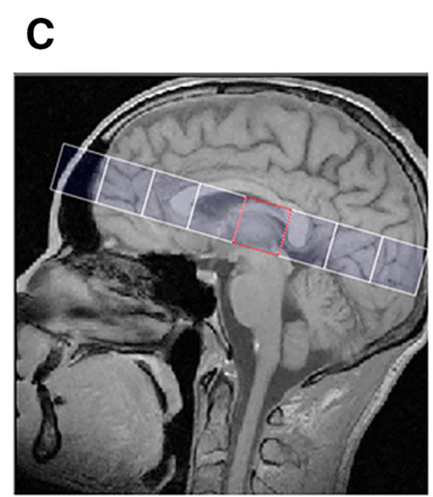

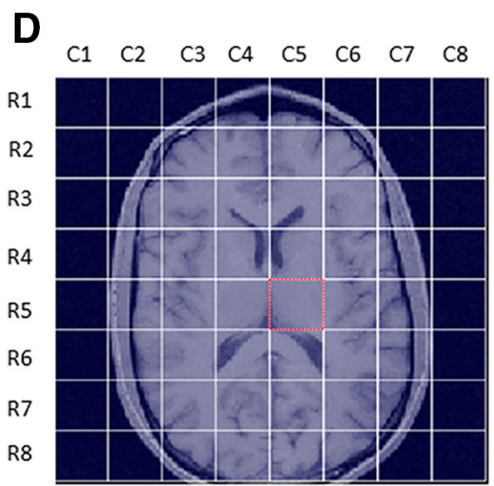

E

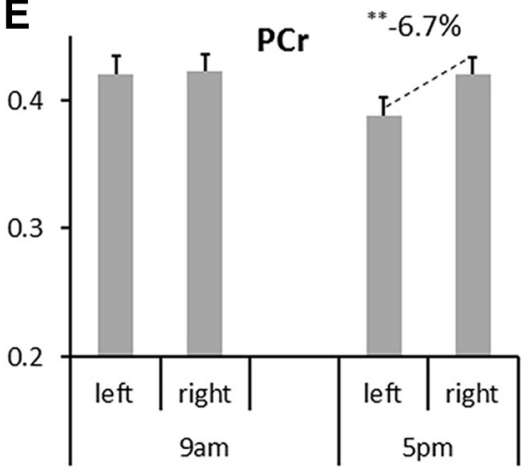

Figure 1. A, Study design. Top, Subjects were measured in two sessions, one in the morning at 9 A.M. and one in the afternoon at 5 P.M. of the same day. After the afternoon 5 P.M. scan at wake state, 15 subjects remained positioned in the scanner and were further measured while napping. Each measurement lasted 20 min. Bottom, 10 controls underwent the same protocol but stayed awake during the second and third scan of the 5 P.M. session. $\boldsymbol{B}_{,}{ }^{31} \mathrm{P}$ spectrum of the left thalamic voxel (R5, C5) after postprocessing with Tarquin. The upper black line represents residuals after fitting. The green and red lines are the fitted and modeled linear combination of monomolecular basic spectra. $C$, Sagittal view with the grid placed parallel to and $2 \mathrm{~mm}$ under the anterior commissure-posterior commissure plane. $D$, Axial 2D flash image in radiological orientation (left hemisphere at the right image side) overlaid with the $\mathrm{CSI}$ grid of $8 \times 8$ voxels. $\boldsymbol{E}$, Comparison of PCr levels in the left (R5C5) and right (R5C4) thalamus voxel. In the morning the intraindividual left-right percentage difference averaged $-1.9 \%$, rising in the afternoon to highly significant $-6.7 \%$. Error bars denote SEM.

MR properties, such as relaxation counterparts given by the biological environment, in vivo $T_{1}$ of PCr, ATP, and Pi had to be determined first to assure optimal matching of the matrix (i.e., other constituents apart from the analytes of interest). The applied CSI sequence differed from other sequences (image-selected in vivo spectroscopy or full saturated recovery) due to rest phasing and nonsaturation effects. Therefore, literature values of the in vivo $T_{1}$ time of ${ }^{31} \mathrm{P}$ compounds could not be applied to the current settings. We performed saturation studies in four subjects to determine the $T_{1}$. The subjects were measured repeatedly in runs of ascending repetition times ( $\mathrm{TR}=550,1000,1700,2500,3000,4000$, $5000,6500,8000,10,000$, and 12,000 ms) which were partitioned onto three sessions while maintaining all other CSI parameters. Curves of the following form (Eq. 1) were fitted to the individual data points of signal integrals at the preselected TR:

$$
M_{z}(t)=M_{z}(0)\left(1-e^{\frac{-t}{T_{1}}}\right)
$$

Up to now, most phantom compositions reported contained $\mathrm{GdCl}_{3}$ and agarose gel as $T_{1}$ and $T_{2}$ modifiers, matching in vivo ${ }^{1} \mathrm{H}$ relaxation rates of brain tissue in $3 \mathrm{~T}$ instruments (Blenman et al., 2006). Some ${ }^{31} \mathrm{P}$ MRS phantom studies have answered basic questions about signal assignment, $\mathrm{pH}$-related and $\mathrm{Mg}^{2+}$-related signal shifts, and fine structures at highspectral resolution (Lu et al., 2014a,b). To calibrate signal integrals in the present settings, phantoms of progressively more complex composition and shape were prepared (Table 1). First $2.5 \mathrm{mM}$ pure $\mathrm{PCr}\left(\right.$ as $\mathrm{Na}_{2} \mathrm{PCr} \times$ $4 \mathrm{H}_{2} \mathrm{O}$ ) were dissolved in $1500 \mathrm{ml} \mathrm{H}_{2} \mathrm{O}$, the $\mathrm{pH}$ adjusted to 7.4 with $\mathrm{HCl}$ and then measured. Then $3.5 \mathrm{mM}$ ATP (as $\mathrm{Na}_{2} \mathrm{ATP}$ ) and $1.0 \mathrm{mM} \mathrm{Pi}$ (as $\mathrm{NaH}_{2} \mathrm{PO}_{4} \times 2 \mathrm{H}_{2} \mathrm{O}$ ) were added and the $\mathrm{pH}$ adjusted with $\mathrm{NaOH}$ to 7.4. Subsequently, solutions with defined concentrations of $\mathrm{Gd}(0.1-25 \mu \mathrm{M}$, as $\left.\mathrm{GdCl}_{3}\right), \mathrm{Mg}\left(1-10 \mathrm{mM}\right.$, as $\left.\mathrm{MgCl}_{2} \times 6 \mathrm{H}_{2} \mathrm{O}\right)$, agarose (0.07-0.6\%), and
Table 1. Relaxation times $\left(T_{1}\right)$ in a mixture of $2.5 \mathrm{mM} \mathrm{PCr}, 3.5 \mathrm{mM}$ ATP, and $1.0 \mathrm{mM}$ Pi while varying type and concentration of modifiers in the matrix

\begin{tabular}{|c|c|c|c|c|c|c|c|}
\hline Concentration & $\begin{array}{l}\mathrm{PCr} \\
T_{1} \text { (ms) }\end{array}$ & $\begin{array}{c}\gamma \text {-ATP } \\
T_{1} \text { (ms) }\end{array}$ & $\begin{array}{l}\mathrm{Pi} \\
T_{1} \text { (ms) }\end{array}$ & Concentration & $\begin{array}{l}\mathrm{PCr} \\
T_{1} \text { (ms) }\end{array}$ & $\begin{array}{l}\mathrm{\gamma} \text {-ATP } \\
T_{1} \text { (ms) }\end{array}$ & $\begin{array}{l}\mathrm{Pi} \\
T_{1} \text { (ms) } \\
\end{array}$ \\
\hline $\mathrm{Gd}(\mu \mathrm{M})$ & & & & $\mathrm{Mg}(\mathrm{mM})$ & & & \\
\hline 0 & 5812 & 5608 & 7269 & 0 & 5812 & 5608 & 7269 \\
\hline 0.1 & 4706 & 1780 & 7300 & 1 & 5365 & 3393 & 7600 \\
\hline 0.2 & 4600 & 1163 & 6820 & 1.5 & & 3636 & 7665 \\
\hline 1 & - & 263 & - & 2 & 5431 & 3566 & - \\
\hline 1.5 & 4200 & - & 6200 & 2.5 & 5401 & 3358 & 6666 \\
\hline 8 & 3501 & - & 4218 & 3.5 & 5693 & 3250 & 6848 \\
\hline 14 & 2093 & - & 2722 & 6 & 4948 & 2499 & 6074 \\
\hline 25 & 1486 & - & 1994 & 10 & 5213 & 1795 & 6300 \\
\hline Agarose (\%) & & & & $\mathrm{K}(\mathrm{mM})$ & & & \\
\hline 0 & 5812 & 5608 & 7269 & 140 & 5061 & 3793 & 7285 \\
\hline 0.07 & 5170 & 1468 & 7253 & & & & \\
\hline 0.2 & 5600 & 765 & 6700 & $\mathrm{~K}+\mathrm{Mg}(\mathrm{mM})$ & & & \\
\hline 0.4 & 5091 & 325 & 4643 & $140+1.5$ & 5016 & 3044 & 6688 \\
\hline 0.6 & 4939 & - & 4161 & & & & \\
\hline
\end{tabular}

At each measurement $1.5 \mathrm{~L}$ of solution adjusted to $\mathrm{pH} 7.4$ was submitted to a ${ }^{31} \mathrm{P}$ spectroscopy saturation study at 13 different repetition times. $T_{1}$ were determined using Equation 1.

$\mathrm{KCl}(140 \mathrm{mM}$ as $\mathrm{KCl})$ were prepared. The resulting concentrations of $\mathrm{Na}$ ranged between 3 and $20 \mathrm{mM}$. If agarose was used, it was heated in 1300 $\mathrm{ml}$ of pure water to dissolve and made up with an aliquot $(200 \mathrm{ml})$ of cold solution containing the scheduled masses of other compounds. All components were not heated together because $12 \mathrm{~min}$ in a conventional microwave oven at $800 \mathrm{~W}$ would have caused $\mathrm{PCr}$ to react to a product appearing as a second peak at $1 \mathrm{ppm}$, accounting for up to $30 \%$ of the total PCr-related signal integral. 
The same $T_{1}$ saturation studies were performed as in vivo with ascending TR and additional steps at 15,000 and 20,000 ms. Once the optimal composition of modifiers was determined, phantoms of $1500 \mathrm{ml}$ volume containing different concentrations of PCr, ATP, and Pi (1-6.4 mM) were prepared and measured to calibrate in vivo results. Finally, an agarose gel preparation $(0.4 \%)$ with in vivo concentrations of close to $2.5 \mathrm{mM}$ PCr, $3.5 \mathrm{mM}$ ATP, and $1.0 \mathrm{mM}$ Pi was sealed into a thin plastic bag and placed into a human skull to match geometry, eventual disturbance of field homogeneity, or signal by the solid encasement and positioning in the coil and MR scanner.

Data processing. All in vivo and phantom Digital Imaging and Communications in Medicine (DICOM) MRS data were analyzed with Tarquin 4.3.10 (Wilson et al., 2011). All data underwent a Fourier transformation and zero and first-order phase correction and were fitted as linear combinations of the simulated metabolic basis set, including PCr, ATP, Pi, phosphoethanolamine (PE), glycerophosphocholine (GPC), and glycerophosphoethanolamine (GPE). While PCr, Pi, PE, GPC, and GPE appear as a singlet Lorentzian peak, signals from the $\alpha$ and $\gamma$ phosphor atoms in ATP were modeled as doublet and $\beta$-ATP as triplet accounting for the homonuclear $j$-coupling (16 $\mathrm{Hz}$ ) with one or two neighbors, respectively.

Even though in vivo signals at the $\gamma$-ATP and $\alpha$-ATP chemical shift position may not originate from ATP alone, but from superpositions with ADP, aminomonophosphate, and other nucleotides, $\gamma$-ATP and not $\beta$-ATP was used due to a better signal-to-noise ratio here. By convention, $\mathrm{PCr}$ was set at $0 \mathrm{ppm}$ as the spectral reference. The $k$-space filter was switched on. The initial $\beta$ value, which determines the mixing ratio of Lorentzian and Gaussian (Voigt) lineshape, was chosen at $1000 \mathrm{~Hz}^{2}$ (Marshall et al., 1997; Lu et al., 2013; Novak et al., 2014) and both the maximum metabolite and the maximum broad shift were set at $3.0 \mathrm{ppm}$. In addition, all ${ }^{31} \mathrm{P}$ spectra were ${ }^{1} \mathrm{H}$ decoupled. In postprocessing, a zero-filling factor of 2 and a line broadening of $10 \mathrm{~Hz}$ were applied. Figure $1 B$ shows one individual ${ }^{31} \mathrm{P}$ spectrum of one voxel covering the left thalamus (row 5, column 5) at 9 A.M. From the chemical shift of the $\mathrm{Pi}$ signal, apparent $\mathrm{pH}$ values were calculated according to the derivative of the Henderson-Hasselbalch equation (Eq. 2; Petroff et al., 1985; Huang et al., 2016) as follows:

$$
p H=6.66+\log \frac{\delta p i-3.08}{5.57-\delta p i}
$$

Statistics. Since the study was longitudinal, the within-subject version of the two-tailed $t$ test was applicable for comparison of means. The variable quality of spectra from voxel to voxel was taken into account by weighting every single data point by the reciprocal square of its absolute $\mathrm{SD}\left(\sigma_{\mathrm{i}}\right)$ put out by the Tarquin software (weighting factor $w_{\mathrm{i}}=1 / \sigma_{\mathrm{i}}{ }^{2}$ ). If combinations of single values at conditions $X$ and $Y$ are considered, they have to be weighted according to the probability of the combination event with a weighting factor $w_{i_{x y}}=1 / \sigma_{i_{x y}}^{2}$ whereby the variance of the combination is as follows:

$$
\sigma_{i_{x y}}^{2}=\sigma_{i_{x}}^{2}+\sigma_{i_{y}}^{2}+2 \cdot \operatorname{Cov}(x, y)
$$

with Cov, covariance of $x, y$;

$$
\operatorname{Cov}(x, y)=\frac{\sum_{i=1}^{n} w_{i x} \cdot\left(x_{i}-\bar{x}\right) \cdot w_{i y} \cdot\left(y_{i}-\bar{y}\right)}{\sum_{i=1}^{n} w_{i x} \cdot w_{i y}}
$$

with $y_{i}$ and $x_{i}$ the individual signal level of $\mathrm{PCr}$, Pi, or $\gamma$-ATP respectively at the respective condition and $\bar{x}, \bar{y}$ weighted averages of individual values at the $x$ and $y$ condition.

The weighted mean difference $\overline{M D}$ of a parameter between two conditions, i.e., 5 P.M. versus 9 A.M. $(n=30)$, Nap1 versus 5 P.M. $(n=15)$, Nap2 versus 5 P.M. $(n=13)$, Wake1 and Wake2 versus 5 P.M. $(n=10)$ calculated throughout subjects for a given voxel as follows (Eq. 3):

$$
\overline{M D}=\frac{\sum_{i=1}^{n} w_{i_{x y}} \cdot\left(y_{i}-x_{i}\right)}{\sum_{i=1}^{n} w_{i_{x y}}}
$$

The weighted SD of differences (SDD) was calculated as follows (Eq. 4):

$$
S D D=\sqrt{\frac{\sum_{i=1}^{n} w_{i_{x y}} \cdot\left[\left(y_{i}-x_{i}\right)-\overline{M D}\right]^{2}}{\left(\sum_{i=1}^{n} w_{i_{x y}}\right)-1}}
$$

The $T$ value is then defined as follows (Eq. 5):

$$
T=\sqrt{n} \cdot \frac{\overline{M D}}{S D D}
$$

The corresponding $p$-value was calculated using the $t, p$ conversion table integrated in Microsoft Excel as tvert( $\operatorname{abs}(t) ; n-2 ; 2)$, with $n-2$ degrees of freedom and two sides (National Institute of Standards and Technology, 1996). Significance thresholds were adjusted according to the Benjamini-Hochberg approach (Holm, 1979; Benjamini and Hockberg, $1995)$ to control for multiple testing. As 16 regions were tested at four conditions, the $\alpha$ thresholds were $0.05 \times 1 / 64 ; 0.05 \times 2 / 64 ; 0.05 \times$ $3 / 64$, and so on.

The logarithmic $\mathrm{pH}$ values were transformed to linear $\left[\mathrm{H}_{3} \mathrm{O}\right]^{+}$concentrations before calculating means, SDs, and differences and thereafter back-transformed to the $\mathrm{pH}$ scale. SDs of individual data points were not available for $\mathrm{pH}$.

\section{Results}

\section{In vivo measurements}

We used ${ }^{31} \mathrm{P}-\mathrm{MRS}$ to investigate levels of PCr, ATP, and Pi in 30 healthy humans at 9 A.M. and 5 P.M. awake and then either after a delay of $7 \mathrm{~min}$ to fall asleep during the first and second $20 \mathrm{~min}$ of an afternoon nap ending at 6 P.M. or as control during continued waking. Spectra were obtained from 16 voxels as listed in Tables 2 and 3. The resulting peak integrals of PCr, ATP, and Pi signals were compared between morning, afternoon, nap, and control conditions. Changes of the three analytes levels and the metabolic ratio $\mathrm{Pi} / \mathrm{PCr}$ between conditions averaged across all subjects are given in Table 2.

In the left thalamus, PCr decreased significantly by $7.0 \pm 0.8 \%$ at 5 P.M. compared with 9 A.M. $\left(p=7.0 \cdot 10^{-6}, t=-5.5, n=30\right.$; Fig. $2 A)$. PCr recovered incompletely $(>80 \%)$ by $5.4 \pm 1.7 \%$ ( $p=0.007, t=3.2$ ) after $20 \mathrm{~min}$ of napping. There was no additional effect with rather higher scatter after 40 min of napping. Pi showed an inverse pattern: an increase at the 5 P.M. condition versus 9 A.M. baseline by $17.1 \pm 5 \%(p=0.005, t=$ 3.1) was followed by a decrease of $15 \pm 6 \%(p=0.02, t=-2.6)$ after a 20 min nap (Fig. $2 B$ ). A course of apparent $\mathrm{pH}$ of 6.98 (95\% CI 6.83-7.08), 6.84 (95\% CI 6.74-6.94), 6.96 (95\% CI $6.86-7.04)$, and 6.95 (95\% CI 6.89-7.01) was calculated for the morning, afternoon, and first and second 20 min of nap conditions (Fig. 2D). Controls showed no significant changes across the three consecutive scans between 5 P.M. and 6 P.M. Here, data from the last scan were more scattered. Percentage changes of $\mathrm{PCr}, \mathrm{Pi}$ levels, $\mathrm{Pi} / \mathrm{PCr}$, and $\mathrm{pH}$ in the left thalamus are indicated in Figure 2.

The PCr/ATP ratio was 1.6 averaged across all voxels, conditions, and individuals. The $\gamma$-ATP signal, a cumulative measure of the nucleotide inventory, underwent no significant change. Importantly, the parameters $\mathrm{PCr}, \mathrm{Pi}$, and $\mathrm{Pi} / \mathrm{PCr}$ (Fig. $3 A$ ) did not show any significant changes in the other investigated voxels. We did not find respective changes in the right thalamus.

In the right occipital and posterior temporal and right insular region, some observed changes with $p<0.05$ did not withstand 
Table 2. Changes of $\mathrm{PCr}$, Pi, and total nucleotides levels ( $\gamma$-ATP signal) throughout 16 voxels awake at 9 A.M., 5 P.M., and while napping $\left(\mathrm{n}_{1}, \mathrm{n}_{2}\right)$ compared to wake controls $\left(w_{1}, w_{2}\right)$

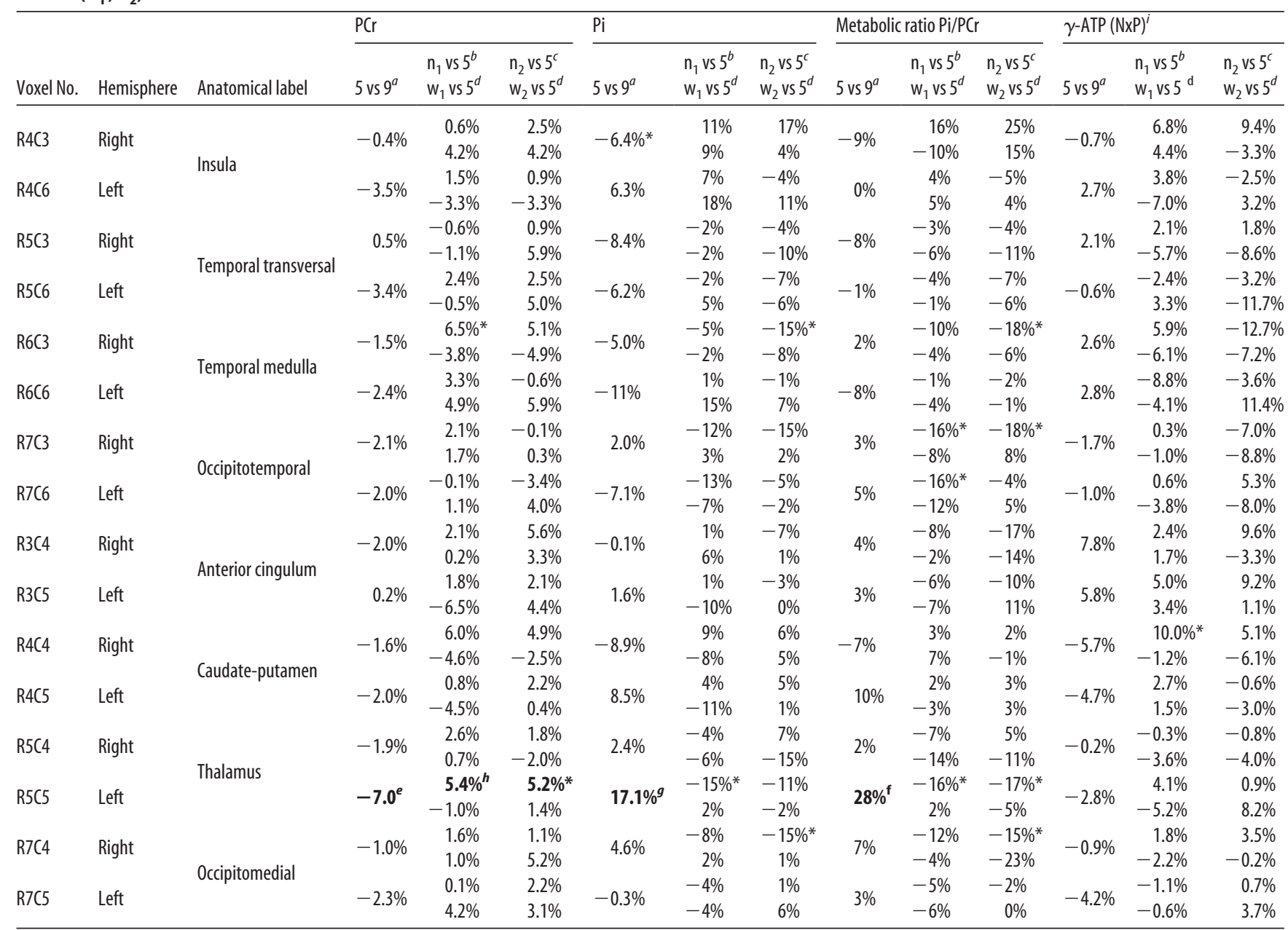

${ }^{a}$ Afternoon (5 P.M.) versus morning (9 A.M.) averaged across 30 subjects

${ }^{b}$ First scan after sleep onset (Nap1) versus awake at afternoon (5 P.M.) averaged across 15 subjects.

'Second scan after sleep onset (Nap2) versus afternoon (5 P.M.) averaged across 13 subjects.

${ }^{d}$ Second and third scan awake versus the first within the 5 P.M. session averaged across 10 control subjects.

${ }^{e}$ Changes with $p$ values of $7.0 \times 10^{-6}$ that survived Benjamini-Hochberg correction.

${ }^{f}$ Changes with $p$ values of $5.0 \times 10^{-5}$ that survived Benjamini-Hochberg correction.

${ }^{9}$ Changes with $p$ values of 0.0046 that survived Benjamini-Hochberg correction.

${ }^{h}$ Changes with $p$ values of 0.007 that did not survive Benjamini-Hochberg correction.

'NxP, minor contributions of any nucleoside phosphate such as ADP, GTP, GDP.

${ }^{*}$ Changes with $p$ values of $0.01<p<0.05$ that did not survive Benjamini-Hochberg correction.

Benjamini-Hochberg corrections (Table 2). Figure $3 B$ illustrates the localization of voxels with significant changes of PCr, $\gamma$-ATP, and Pi at 5 P.M. and after the nap.

In the thalamus a significant left-right side difference became apparent only in the afternoon $\left(-6.7 \pm 1.3 \%, p=1.6 \cdot 10^{-5}, t=\right.$ $-6.8)$ but not in the morning $(-1.9 \pm 1.4 \%, p=0.3, t=-1.2, n=$ 30; Fig. $1 E$ ). Conversely, the right temporal medullar and transveral hemispheric PCr significantly exceeded the left at all conditions (see Fig. 4; Table 3) by an average of 7.4\%. However, the latter findings outside the isocenter may be interpreted in view of spatial field inhomogeneities and different fractions of gray matter, white matter, and CSF included in the voxel homologues.

The average between-subject variabilities across all regions, conditions, and subjects were characterized by coefficients of variation of $13.5 \%$ for PCr, $24.3 \%$ for the Pi signal, and $10.1 \%$ for the $\gamma$-ATP signal. Scatter plots of individual data points are given in Figure 5.

\section{Reproducibility and reliability}

Two subjects underwent the entire protocol of morning, afternoon, and nap scans twice on 2 different days. The coefficient of variation for repeated measurements at equivalent conditions was 3.1\% for the left thalamic region (two replicates and two subjects). PCr level changes in the thalamus voxel between the morning and afternoon conditions were -4.5 and $-3.9 \%$ in Subject 1 and $-5.7 \%$ and $-8.0 \%$ in Subject 2, respectively. To exclude any left-right asymmetry of the instrumentation, Subject 2 was scanned in prone and in supine positions at either condition. Clearly, regardless of whether the voxel's position was left or right from the isocenter of the scanner, it was constantly the left thalamus voxel that showed lower PCr values than the contralateral thalamus and a decrease of $\mathrm{PCr}$ in the afternoon scan. The respective decrease amounted to -5 or $-6 \%$ in the supine and prone position, respectively. Repeated measurements of a reference phantom containing $2.7 \mathrm{mM}$ PCr at 9 A.M. and 5 
Table 3. Comparison of $\mathrm{PCr}$, $\mathrm{Pi} / \mathrm{PCr}$, and total nucleotides ( $\gamma$-ATP signal) levels in the left hemisphere versus right hemisphere throughout eight pairs of homologue voxels and throughout conditions awake at 9 A.M., 5 P.M., while napping (Nap1, Nap2) and in wake controls (Wake1, Wake2)

\begin{tabular}{|c|c|c|c|c|c|c|c|c|c|c|c|c|c|}
\hline \multirow[b]{2}{*}{ Voxel No. } & \multirow[b]{2}{*}{ Region } & \multicolumn{4}{|l|}{$\mathrm{PCr}$} & \multicolumn{4}{|c|}{ Metabolic ratio Pi/PCr } & \multicolumn{4}{|c|}{$\gamma$-ATP (NxP) } \\
\hline & & 9 A.M. & 5P.M. & $\begin{array}{l}\text { Nap1 } \\
\text { Wake1 }\end{array}$ & $\begin{array}{l}\text { Nap2 } \\
\text { Wake2 }\end{array}$ & 9 A.M. & 5P.M. & $\begin{array}{l}\text { Nap1 } \\
\text { Wake1 }\end{array}$ & $\begin{array}{l}\text { Nap2 } \\
\text { Wake2 }\end{array}$ & 9 A.M. & 5P.M. & $\begin{array}{l}\text { Nap1 } \\
\text { Wake1 }\end{array}$ & $\begin{array}{l}\text { Nap2 } \\
\text { Wake2 }\end{array}$ \\
\hline $\begin{array}{l}\text { R5C6 } \\
\text { vs R5C3 }\end{array}$ & Temporal transversal & $-6 \%^{c}$ & $-6.4 \%^{d}$ & $\begin{array}{l}-6.8 \%^{d} \\
-7.5 \%^{*}\end{array}$ & $\begin{array}{l}-10 \%^{d} \\
-1.3 \%\end{array}$ & $-7.8 \%$ & $-7.7 \%$ & $\begin{array}{r}6.9 \% \\
-6.1 \%\end{array}$ & $\begin{array}{r}-2.5 \% \\
1.7 \%\end{array}$ & $-5.7 \%$ & $3.5 \%$ & $\begin{array}{l}-4.1 \% \\
-24 \%^{d}\end{array}$ & $\begin{array}{l}-2.6 \% \\
-16 \%{ }^{d}\end{array}$ \\
\hline $\begin{array}{l}\text { R7C6 } \\
\text { vs R7C3 }\end{array}$ & Occipitotemporal & $2.1 \%$ & $-7.8 \%$ & $\begin{array}{r}3.2 \% \\
-2.6 \%\end{array}$ & $\begin{array}{l}-3.7 \% \\
-3.1 \%\end{array}$ & $-3.7 \%$ & $-2 \%$ & $\begin{array}{c}7.8 \% \\
-17.6 \%\end{array}$ & $\begin{array}{l}13.2 \% \\
12.4 \%\end{array}$ & $-5.2 \%$ & $-1.6 \%$ & $\begin{array}{l}-12 \% \\
18.3 \%\end{array}$ & $\begin{array}{l}0.9 \% \\
4.2 \%\end{array}$ \\
\hline $\begin{array}{l}\mathrm{R} 3 \mathrm{C} 5 \\
\text { vs } \mathrm{R3C4}\end{array}$ & Anterior cingulum & $-5.7 \%$ & $-5.1 \%$ & $\begin{array}{l}4 \% \\
5 \%\end{array}$ & $\begin{array}{l}6.7 \% \\
12.3 \%\end{array}$ & $8.1 \%$ & $10 \%$ & $\begin{array}{l}2.3 \% \\
16.2 \%\end{array}$ & $\begin{array}{l}12 \% \\
3.4 \%\end{array}$ & $4.4 \%$ & $-2 \%$ & $\begin{array}{c}7.6 \\
-0.9 \%\end{array}$ & $\begin{array}{r}0.8 \% \\
-2.3 \%\end{array}$ \\
\hline $\begin{array}{l}\text { R4C5 } \\
\text { vs R4C4 }\end{array}$ & Caudate-putamen & $2.7 \%$ & $2 \%$ & $\begin{array}{l}1.2 \% \\
6.4 \%\end{array}$ & $\begin{array}{l}3.4 \% \\
5.4 \%\end{array}$ & $-9 \%$ & $6.4 \%$ & $\begin{array}{c}5.7 \% \\
-15.5 \%\end{array}$ & $\begin{aligned} & 13.7 \% \\
- & 4.9 \%\end{aligned}$ & $4.12 \%$ & $1.3 \%$ & $\begin{array}{c}3.1 \% \\
-12.4 \%\end{array}$ & $\begin{array}{l}-1 \% \\
-0.5 \%\end{array}$ \\
\hline
\end{tabular}

The numbers of subjects $n$ were the same as in Table 2 .

${ }^{a} p$ values of $7.0 \times 10^{-5}<p<6.5 \times 10^{-5}$ that survived Benjamini-Hochberg correction.

${ }^{b} p$ values of $4.1 \times 10^{-4}<p<4.0 \times 10^{-4}$ that survived Benjamini-Hochberg correction.

c $p$ values of $7.0 \times 10^{-4}$

${ }^{d} p$ values of $0.0011<p<0.0074$ that survived Benjamini-Hochberg correction.

${ }^{e} \mathrm{NxP}$, minor contributions of any nucleoside phosphate such as ADP, GTP, GDP.

${ }^{*} p$-values of $0.01<p<0.05$ that did not survive Benjamini-Hochberg correction.

A

Signal Int.

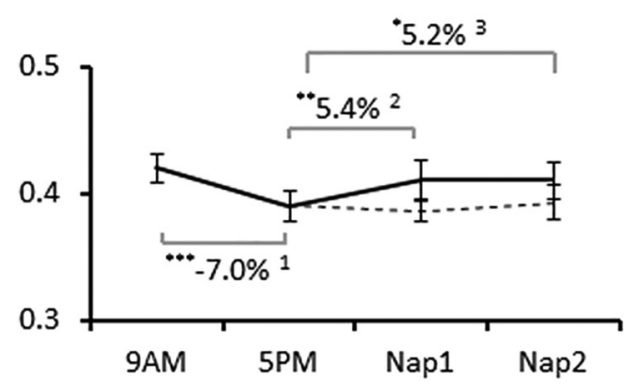

Cignal Int.

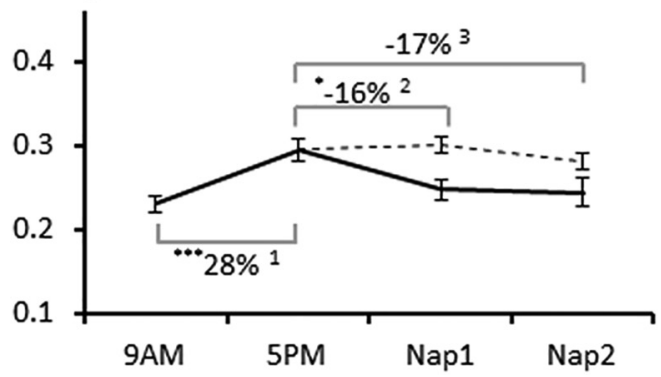

B

Signal Int.

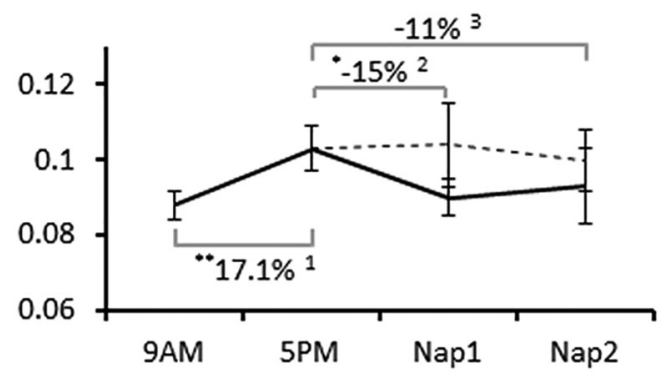

D $\quad$ pH

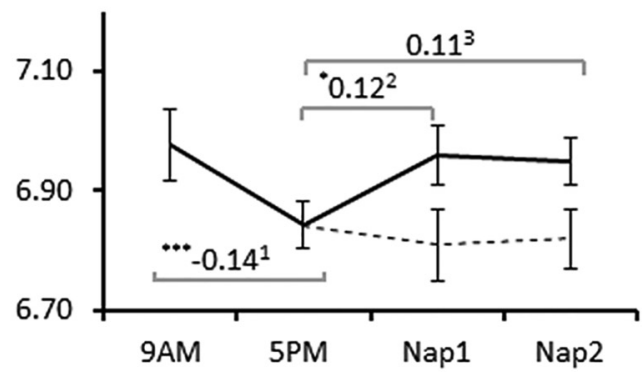

Figure 2. $\quad \boldsymbol{A}-\boldsymbol{D}$, Plots of the courses of $\mathrm{PCr}(\boldsymbol{A}), \mathrm{Pi}(\boldsymbol{B})$, metabolic ratio $\mathrm{Pi} / \mathrm{PCr}(\boldsymbol{C})$, and pH level $(\boldsymbol{D})$ in the left thalamus $15.6 \mathrm{ml}$ voxel throughout the four conditions assessed. Dotted lines represent the control group that did not nap. Note the inverse course of $\mathrm{Pi}$ and $\mathrm{Pi} / \mathrm{PCr}$ versus $\mathrm{PCr}$ and $\mathrm{pH}$, respectively.

P.M. on 3 different days showed a coefficient of variation of $\mathrm{PCr}$ levels of $0.6 \%$.

\section{Origin of ${ }^{31} \mathrm{P}$-MRS signals}

At the present medium field regime of $B_{0} \approx 3 \mathrm{~T}$, the dipolar interaction and not the chemical shift anisotropy (CSA) can be considered as the prevailing relaxation mechanism (Cohen and Burt, 1977; Evelhoch et al., 1985; Mathur-De Vré et al., 1990). In our study, the addition of ATP and Pi did not affect the $T_{1}$ relaxation time of PCr. Hence, it can be assumed that ${ }^{1} \mathrm{H}_{-}{ }^{31} \mathrm{P}$ intermolecular dipol-dipol interaction (DD) with $\mathrm{H}_{2} \mathrm{O}$ contributed most to the relaxation of $\mathrm{PCr}$. As intramolecular protons are not 

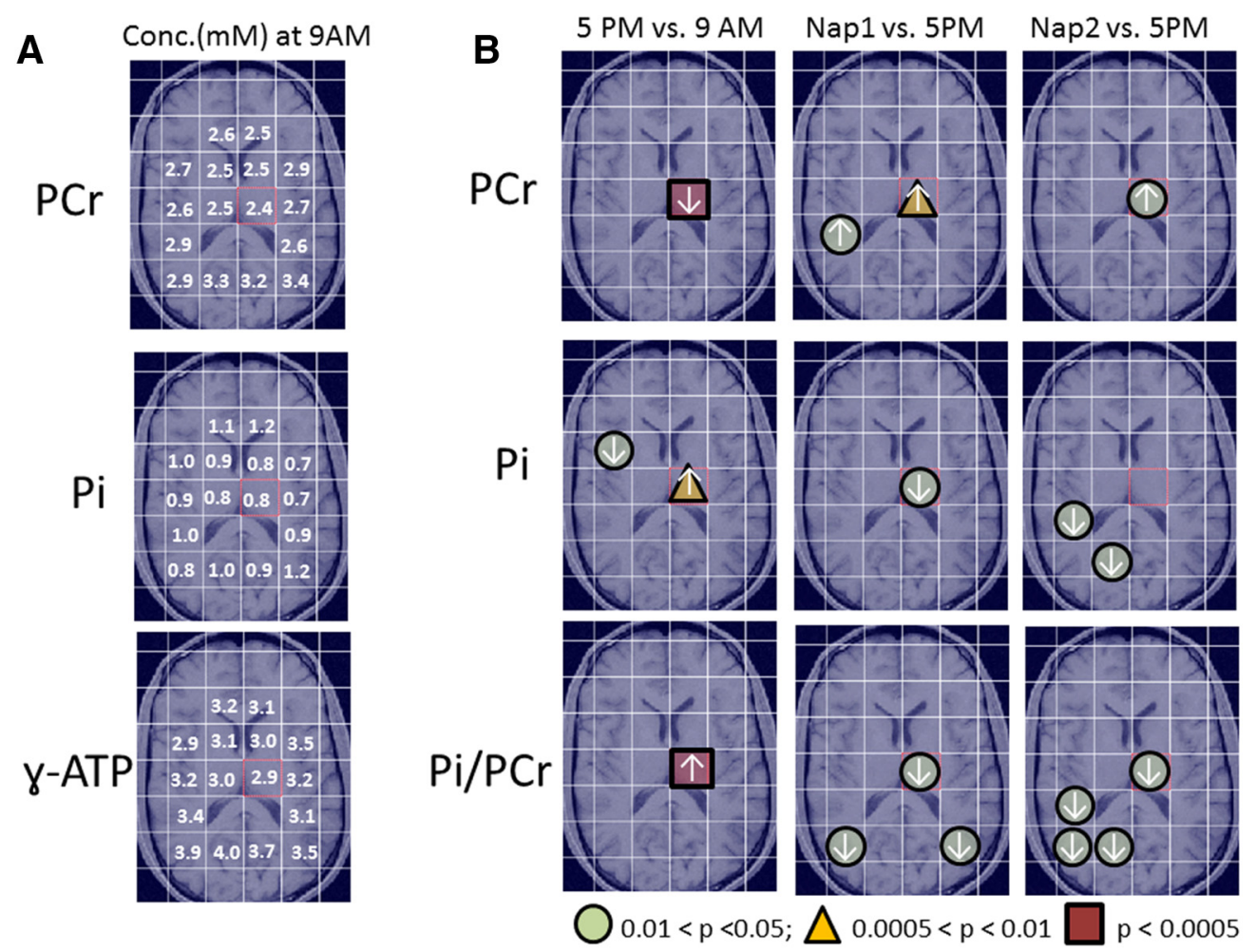

Figure 3. A, Voxelwise concentrations of PCr, Pi, and $\gamma$-ATP at 9 A.M. B, Localization of the observed significant changes between conditions within the CSI grid overlaid onto an axial MRI.

adjacent to the heteronucleus ${ }^{31} \mathrm{P}$, the intramolecular DD can be neglected. Also, contributions of the spin rotation and the scalar relaxation can be neglected in small $\mathrm{P}$ molecules.

With respect to subcellular localization, the cytosol with a viscosity approximately the same as water [0.7-2.0 centipoise $(\mathrm{cP})$ ] provides a high mobility of ${ }^{31} \mathrm{P}$ metabolites and short correlation times $(\tau)$ in contrast to mitochondria with a viscosity of $>100 \mathrm{cP}$ (Luby-Phelps, 2000). Apparent diffusion ranges of $\mathrm{PCr}$ were estimated at $2 \mu \mathrm{m}$ in the mitochondrial matrix and at $\approx 66$ $\mu \mathrm{m}$ within the cytosol with diffusion coefficients of $D_{\mathrm{PCr}}=$ $0.08 \times 10^{-3} \mathrm{~mm}^{2} / \mathrm{s}$ and $0.28 \times 10^{-3} \mathrm{~mm}^{2} / \mathrm{s}$, respectively (Gabr et al., 2011). Furthermore, due to the composition of membrane folds (cristae) in stack-like arrangements every $40-100 \mathrm{~nm}$ and small overall size $(0.7-3.0 \mu \mathrm{m})$, the mitochondria provide multiple ${ }^{31} \mathrm{P}$ relaxation partners causing very short relaxation times and low ${ }^{31} \mathrm{P}$ signals. While ATP is produced at the matrix site of the ATP-synthase and thus concentrated in the mitochondrial $\mathrm{M}$-space, the mitochondrial isoform of creatin kinase is localized between inner and outer membrane in the mitochondrial $\mathrm{C}$-space. Thus the C-space is the site of production of $\mathrm{PCr}$ (Wallimann et al., 1992). Space there is even narrower $(\approx 2-20 \mathrm{~nm}$ width) and thus diffusion is more restricted. Hence, it can be concluded that the received MRS signals of PCr and ATP are of almost exclusive intracellular cytosol localization and thus are the receivid MRS signals.

Regarding $\mathrm{Pi}$, at $7 \mathrm{~T}$ additional $\mathrm{Pi}$ signals with shorter $T_{1}$ could be differentiated at $\sim 5.2 \mathrm{ppm}$ from the major Pi signal at $4.8 \mathrm{ppm}$ and assigned to more alkaline and viscous compartments, such as mitochondria ( $\mathrm{pH} \approx 7.9$; Kan et al., 2010). Comparing different pharmacologic interventions versus baseline, other Pi signals could be attributed to extracellular space $(\mathrm{pH} \approx 7.3)$ at $7 \mathrm{~T}$ (Gilboe et al., 1998). Such fine structures could not be resolved by our $3 \mathrm{~T}$ equipment. The model implemented in Tarquin uses a $\mathrm{Pi}$ basic signal centered at $4.8 \mathrm{ppm}$ and thus may largely reflect cytosolic Pi ( $\mathrm{pH} \approx 7.0$; Gilboe et al., 1998).

A further issue is the mutual contribution of white matter and gray matter to the received ${ }^{31} \mathrm{P}$ signal. As mentioned in the introduction, Plante and coworkers (2014) extrapolated PCr levels in pure white matter and pure gray matter by linear regression of ${ }^{31} \mathrm{P}$ signals and tissue type fraction over 84 voxels. At baseline, nonsignificantly slightly higher PCr levels in white matter (4.06) than in gray matter (3.94) were reported. They observed a nonsignificant decrease of PCr by $3.9 \%$ from baseline to SD and a significant increase by $7.3 \%$ to recovery sleep in gray matter and no effect in white matter. A similar regression analysis at baseline of Hetherington et al. (2001) yielded 3.53 mM PCr in gray matter and $3.33 \mathrm{mM} \mathrm{PCr}$ in white matter, not differing significantly. Also, we determined the fraction of gray matter, white matter, and CSF in each voxel by readout of an analog grid in coregistered and segmented MPRAGE images as presented in Table 4. Group averages of tissue fractions were almost identical in homologous left and right hemispheric voxels and no correlation of hemispheric differences in signals of $\mathrm{PCr}, \mathrm{Pi}$, and $\mathrm{Pi} / \mathrm{PCr}$, and of gray matter and white matter fractions could be observed. The major constituent of the thalamus voxel in our study was white matter $(67 \%)$. Whereas individual differences between left and right averaged $0.9 \%$ for gray matter and $-2.8 \%$ for white matter here, PCr differed by $-1.9 \%$ at baseline and $-6.7 \%$ at 5 P.M. In the temporal voxels R5C6 versus R5C3 and R6C6 versus R6C3, gray matter differed by -0.2 and $-3.1 \%$, respectively, and white matter by 1.0 and $2.6 \%$, whereas static side differences of PCr averaged -6.4 and $-8.5 \%$ (i.e., right dominating). Thus, it can be concluded that $\mathrm{PCr}$ is affected much more by functional issues than by structural issues. 


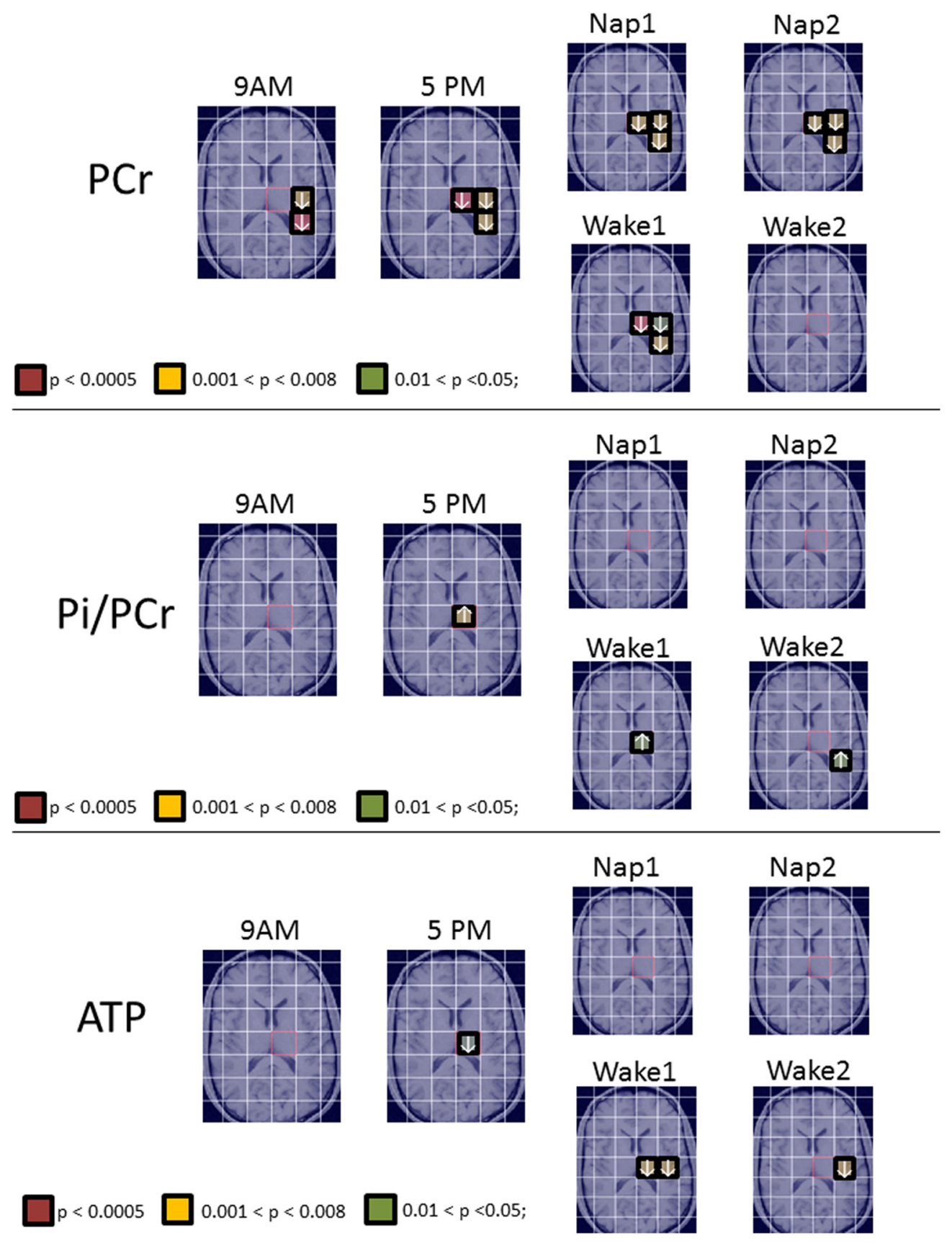

Figure 4. Illustration of voxels displaying significant left-right hemispheric differences of PCr, Pi/PCr, and ATP level throughout 16 voxels at 9 A.M. and 5 P.M. for all subjects, while napping (Nap1, Nap2) for napping subjects, and while awake for wake controls (Wake1, Wake2).

\section{Quantitation and in vitro validation}

Figure $6 A$ shows ${ }^{31} \mathrm{P}$-MRS signal saturation studies, curve fits, and resulting $T_{1}$ of four subjects. The resulting average in the left thalamus voxel was $T_{1}=3464 \pm 371 \mathrm{~ms}$ for PCr, $T_{1}=1840 \pm$ $518 \mathrm{~ms}$ for ATP, and $T_{1}=2717 \pm 462 \mathrm{~ms}$ for Pi. Consistent with variations of the water content of the brain tissue throughout regions, different $T_{1}$ values were observed in different $(25 \mathrm{~mm})^{3}$ voxels. Short $T_{1}$ values were observed in the thalamus voxel, which contained a high fraction of white matter $(67 \%)$, whereby longer relaxation times occurred in the voxels covering the left insula $\left(T_{1}=3733 \pm 480 \mathrm{~ms}\right.$, R4C6) or the posterior cingulum $\left(T_{1}=3708 \pm 673 \mathrm{~ms}\right.$, R6C5) with a higher amount of gray matter (62 and 39\%, respectively) and CSF (13 and 28\%, respectively). Measurements of progressively more complex phantoms conse- quently followed $\mathrm{pH}$ adjustment to 7.4 and started with $2.5 \mathrm{mM}$ pure PCr in water yielding $T_{1}=6062 \pm 253 \mathrm{~ms}$. Next $3.5 \mathrm{mM}$ ATP and $1.0 \mathrm{mM}$ Pi were added, resulting in $T_{1}=5812 \pm 500 \mathrm{~ms}$ for PCr, $T_{1}=5608 \pm 97 \mathrm{~ms}$ for ATP, and $T_{1}=7269 \pm 16 \mathrm{~ms}$ for $\mathrm{Pi}$. The in vivo $T_{1}$ of $\mathrm{PCr}$ of $3464 \pm 371 \mathrm{~ms}$ to $3733 \pm 480 \mathrm{~ms}$ found by us was close to the literature range of $2700-3570 \mathrm{~ms}$ reported by Blenman et al. (2006). The observed in vivo testretest coefficient of variation $(\mathrm{CV})$ of $3.1 \%$ outperformed the interassay intraindividual CV of $4.2 \%$ reported by Kato et al. (1994).

Because complexes of ATP and Mg have been reported as active species in vivo (Cohen and Burt, 1977), we also studied $\mathrm{Mg}$ as matrix additive. Here variations of concentrations of $\mathrm{Mg}^{2+}$ (1-10 $\mathrm{mM})$ and the addition of $140 \mathrm{mM} \mathrm{KCl}$ to mimic cytosol 
A
B
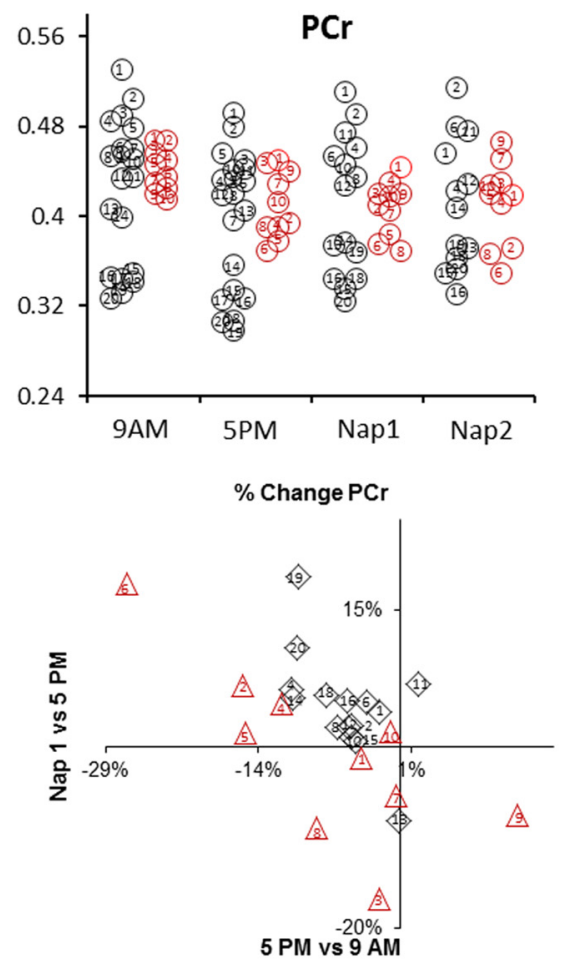
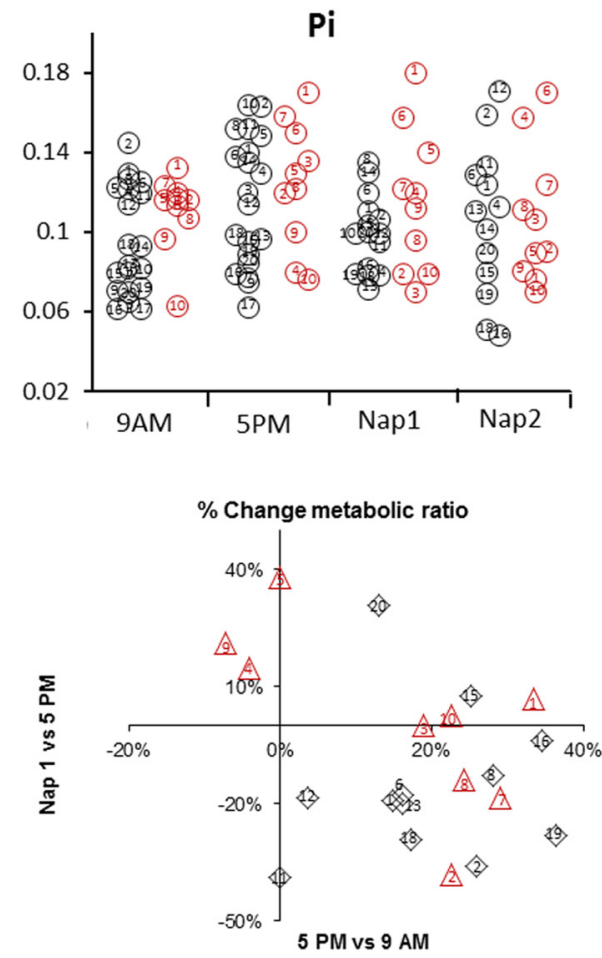

Figure 5. A, Scatter plots of individual changes of $\mathrm{PCr}$ and Pi in the left thalamus throughout four conditions for both subjects who napped (black circles) and controls (red circles). $\boldsymbol{B}$, Individual changes of $\mathrm{PCr}$ and Pi/PCr in nap versus wake at 5 P.M. plotted as a function of changes in awake state in the course of the day (5P.M. vs 9 A.M.). Red triangles represent the respective changes within the control group that stayed awake during all four scans and black diamonds the group that napped. Note the vertical shift between the test and control cluster of data points.

Table 4. Fractions of gray matter, white matter, and CSF within each voxel, extracted from segments of coregistered MPRAGE datasets, averages across 18 subjects

\begin{tabular}{|c|c|c|c|c|c|c|c|c|}
\hline \multirow[t]{2}{*}{ Voxel No. } & \multirow[t]{2}{*}{ Hemisphere } & \multirow[t]{2}{*}{ Anatomical label } & \multicolumn{3}{|c|}{ Average fraction } & \multicolumn{3}{|l|}{ SD } \\
\hline & & & Gray matter & White matter & CSF & Gray matter & White matter & CSF \\
\hline R4C3 & Right & Insula & 0.63 & 0.22 & 0.14 & 0.05 & 0.06 & 0.04 \\
\hline $\mathrm{R} 5 \mathrm{C} 6$ & Left & Temporal transversal & 0.54 & 0.38 & 0.08 & 0.08 & 0.08 & 0.03 \\
\hline $\mathrm{R} 6 \mathrm{C} 3$ & Right & \multirow{2}{*}{ Temporal medulla } & 0.34 & 0.58 & 0.07 & 0.08 & 0.06 & 0.05 \\
\hline R6C6 & Left & & 0.31 & 0.61 & 0.08 & 0.06 & 0.05 & 0.05 \\
\hline R3C4 & Right & \multirow{2}{*}{ Anterior cingulum } & 0.34 & 0.60 & 0.06 & 0.04 & 0.05 & 0.03 \\
\hline $\mathrm{R} 3 \mathrm{C5}$ & Left & & 0.36 & 0.56 & 0.08 & 0.06 & 0.07 & 0.03 \\
\hline R4C4 & Right & \multirow{2}{*}{ Caudate-putamen } & 0.43 & 0.42 & 0.15 & 0.03 & 0.05 & 0.06 \\
\hline R4C5 & Left & & 0.42 & 0.40 & 0.18 & 0.04 & 0.06 & 0.06 \\
\hline $\mathrm{R} 5 \mathrm{C} 4$ & Right & \multirow{2}{*}{ Thalamus } & 0.24 & 0.68 & 0.08 & 0.03 & 0.05 & 0.03 \\
\hline $\mathrm{R} 5 \mathrm{C5}$ & Left & & 0.25 & 0.65 & 0.10 & 0.03 & 0.06 & 0.04 \\
\hline
\end{tabular}

barely influenced $T_{1}$ of PCr and Pi (Fig. 6B). In agreement with Cohen and Burt (1977), $\mathrm{Mg} \leq 10 \mathrm{mM}$ increased the relaxation rate of $\mathrm{PCr}$ and $\mathrm{Pi}$ by $<16 \%$. In contrast, relaxation rates of the $\gamma$-ATP signal considerably increased with increasing Mg concentrations by $\leq 68 \%$. However, short $T_{1}$ as observed in vivo could not be reached at $\mathrm{Mg}$ concentrations in the relevant range of $0.5-2 \mathrm{mM}$ and also not by combination of $\mathrm{Mg}, \mathrm{K}$, and $\mathrm{Cl}$ (Table 1). Thus, macromolecular and viscosity factors must also account for the shortening of $\gamma$-ATP $T_{1}$ in vivo.

Subsequently, to reach in vivo conditions, a series of measurements with $T_{1}$ modifiers, i.e., $\mathrm{Gd}(0.07-25 \mu \mathrm{M})$ and agarose gel $(0.07-0.6 \%)$, were conducted. In contrast to $\mathrm{Mg}$, the paramagnetic $T_{1}$ modifier $\mathrm{Gd}(0.07-25 \mu \mathrm{M})$ and the viscous agarose caused a stronger $T_{1}$ shortening effect within increasing concentrations (Fig. 6C,D). Noteworthy here is the strong increase of the relaxation rate $\left(1 / T_{1}\right)$ of $\gamma$-ATP, in contrast to $\mathrm{PCr}$ and Pi. This can be explained by the restricted mobility of the large, multiply charged ATP molecule and the associated higher correlation time. Similarly, in the cytosol, polar macromolecules reduce ATP diffusion $\left(D_{\mathrm{ATP}}=0.15 \mathrm{~mm}^{2} / \mathrm{s}\right.$; Crank, 1976). Diffusion coefficients of PCr and Pi in 1\% agarose gel $\left(D_{\mathrm{PCr}}=0.76 \times 10^{-3} \mathrm{~mm}^{2} / \mathrm{s}, D_{\mathrm{Pi}}=0.78 \times 10^{-3}\right.$ $\mathrm{mm}^{2} / \mathrm{s}$ ) that equaled $D_{\mathrm{PCr}}$ in water (Gabr et al., 2011) were in agreement with the minimal effect of agarose on $T_{1}$ of $\mathrm{PCr}$ and $\mathrm{Pi}$ in our study. Thus, we did not observe differences in the $T_{1}$ behavior of ATP, PCr, and Pi that could be explained by dif- 
A

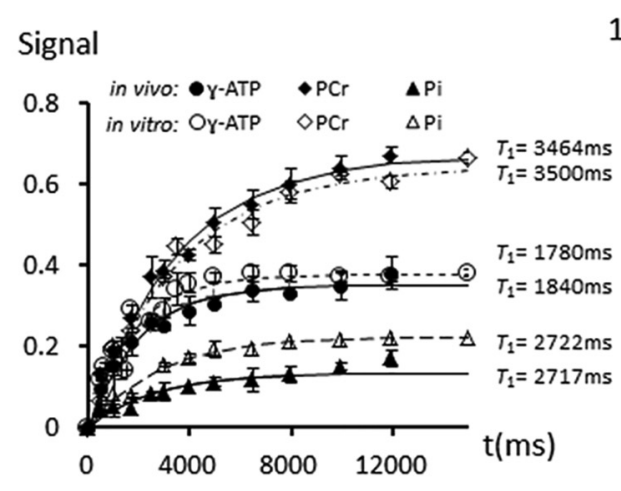

B

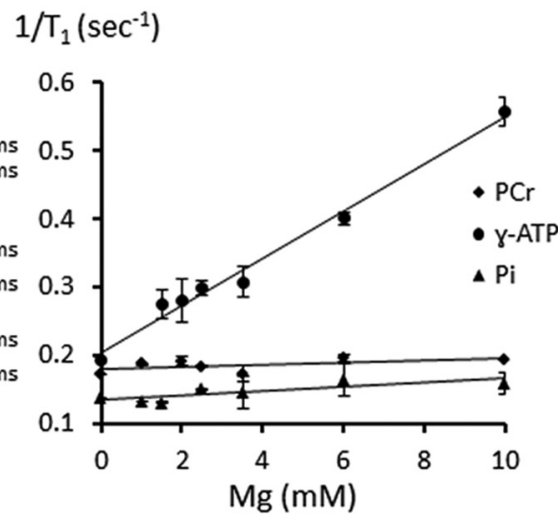

C

$$
1 / T_{1}\left(\sec ^{-1}\right)
$$

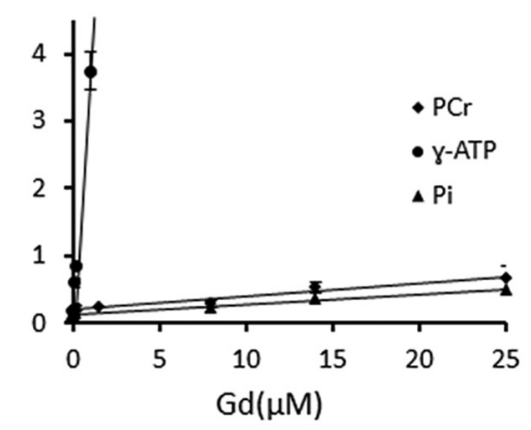

$\mathbf{F}$

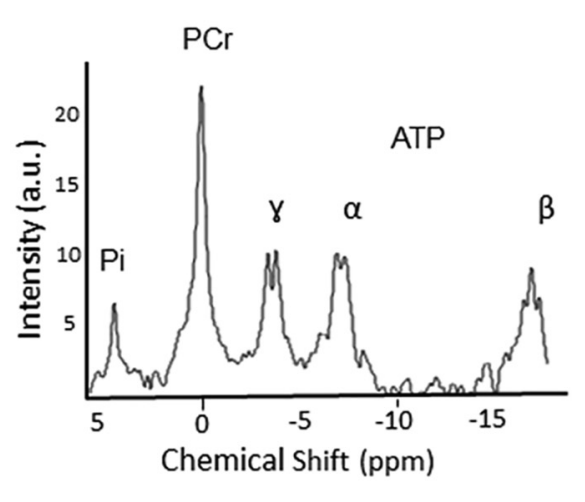

Figure 6. $\quad{ }^{31} \mathrm{P}-\mathrm{MRS}$ signal saturation studies of $\mathrm{PCr}, \gamma$-ATP, and $\mathrm{Pi}$, of relaxation times $\left(T_{1}\right)$, and of relaxation rates $\left(1 / T_{1}\right)$ : $A$, Comparison of saturation curves in vivo in four subjects with those of best matching phantom preparations containing all $2.5 \mathrm{mMPCr}, 3.5 \mathrm{mM} \mathrm{ATP}$, and $1.0 \mathrm{mM}$ Piand $8 \mu M \mathrm{Gd}$ for PCr, $0.1 \mu M$ Gd for ATP, and $14 \mu M$ Gd for Pi. $B-D$, Relaxation rate (1/T $T_{1}$ ) of PCr, $\gamma$-ATP, and $\mathrm{Pi}$ in solutions with different concentrations of $\mathrm{Mg}^{2+}(1-10 \mathrm{mM}), \mathrm{Gd}(0.07-25 \mu \mathrm{M})$ and agarose (0.07-0.6\%). E, Calibration lines for PCr (diamond), ATP (circle) and Pi (triangle) signal covering the concentration range 1-6.4 mM measured at TR $=3000 \mathrm{~ms}$ (filled symbols) and at saturated level with TR $=20000 \mathrm{~ms}$ (open symbols). The in vivo PCr, $\gamma$-ATP and Pi level in the thalamus region at $9 \mathrm{AM}$ corresponded to a concentration of $2.40,2.91$ and $0.8 \mathrm{mM}(n=30)$, respectively. Error bars indicate $S E M$. $\boldsymbol{F}$, ${ }^{31} P$ spectrum of the R5, $C 5$ voxel of a phantom containing 2.5 mM PCr, 3.5 mM ATP, $1.0 \mathrm{mM} \mathrm{Pi} \mathrm{and} \mathrm{0.44 \%} \mathrm{agarose} \mathrm{placed} \mathrm{inside} \mathrm{a} \mathrm{human} \mathrm{skull.}$

ferential structure-related CSA effects in addition to global matrix-induced effects.

In vivo conditions were best matched at $8 \mu \mathrm{M}$ Gd for $\mathrm{PCr}$ $\left(T_{1}=3501 \pm 148 \mathrm{~ms}\right)$, which was half of that reported for ${ }^{1} \mathrm{H}$ MRS, in line with the methodological differences (Blenman et al., $2006)$ at $0.1 \mu \mathrm{M} \mathrm{Gd}$ for $\operatorname{ATP}\left(T_{1}=1780 \pm 170 \mathrm{~ms}\right)$ and at $14 \mu \mathrm{M}$ Gd for Pi $\left(T_{1}=2722 \pm 22 \mathrm{~ms}\right.$; Fig. $\left.6 A\right)$. Using these measurements, two calibration curves of each metabolite, one at TR $=$ $3000 \mathrm{~ms}$ as used in vivo and one at the saturated level of $\mathrm{TR}=$ $20,000 \mathrm{~ms}$, were obtained from phantoms with concentrations of 1.6, 2.5, 3.5, 5.0, and 6.4 mM PCr and of 2.0, 3.5, 5.0, and $6.4 \mathrm{mM}$ ATP and Pi (Fig. 6E). Furthermore, to study effects of the geometry and homogeneity of the sample onto the signal, a preparation of $2.5 \mathrm{mM}$ PCr, $3.5 \mathrm{mM}$ ATP and $1 \mathrm{mM}$ Pi and $0.44 \%$ agarose was placed inside a human skull. This yielded the same PCr, ATP, and Pi peak integrals as the preparation in a cubic plastic container (Fig. 6F). Each concentration was measured three times. Application of this calibration curve to in vivo data $(\mathrm{TR}=3000 \mathrm{~ms})$ of $n=13$ subjects who napped and underwent all four scans yielded a left thalamus concentration of $2.57 \pm 0.09 \mathrm{mM}$ for PCr, $2.91 \pm$ $0.08 \mathrm{mM}$ for ATP, and $0.81 \pm 0.04 \mathrm{mM}$ for Pi at baseline in the morning, a PCr level of $2.41 \pm 0.09 \mathrm{mM}$ in the afternoon, and $2.54 \pm 0.09 \mathrm{mM}$ and $2.53 \pm 0.09 \mathrm{mM}$ during the first and second 20 min nap (Nap1 and Nap2). The respective concentrations of Pi at 5 P.M., Nap1, and Nap2 were 0.97, 0.82, and $0.86 \pm 0.04$
$\mathrm{mM}$. The measurement of the phantom calibration series yielded a precision, expressed as relative SDs of PCr of 3.73\%, ATP of $6.4 \%$, and $\mathrm{Pi}$ of $5.6 \%$ averaged over all concentrations studied. In the $n=4$ subjects in whom entire saturation studies were conducted, application of the calibration line established for standard unsaturated conditions $(\mathrm{TR}=3000 \mathrm{~ms}$ ) to the in vivo signals acquired at $3000 \mathrm{~ms}$ yielded concentrations of $2.36 \mathrm{mM}$ PCr. The calibration line established for saturated conditions $(12,000 \mathrm{~ms})$ to the in vivo data acquired at $12,000 \mathrm{~ms}$ yielded 2.16 $\mathrm{mM}$ PCr. The concentrations in the remaining voxels were calculated by applying calibration lines established for each voxel to the respective MRS signal (Fig. 3A).

\section{Plausibility of outcomes in view of current literature}

The brain consists of approximately 79\% intracellular and 21\% extracellular space, (Nioka et al., 1991) the latter including and resembling CSF. PCr and ATP are of almost exclusive intracellular localization and thus is the received MRS signal. The total concentration of $\mathrm{PCr}$ has been reported to be $2.5 \mathrm{mM}$ in the brain (Nioka et al., 1991) and $0.04 \mathrm{mM}$ in CSF (Agren and Niklasson, 1988; Rao et al., 2018). The concentration of ATP in the brain was $3.0 \mathrm{mM}$. Meanwhile, the concentrations of ATP, ADP, and AMP in CSF were below the detection limit at $0.05 \mu \mathrm{M}$ (Harkness et al., 1984). In muscular interstitial fluid, the concentration of ATP was $0.113 \mu \mathrm{M}$, the concentration of ADP was $0.052 \mu \mathrm{M}$, and the 
concentration of AMP was 0.351 $\mu \mathrm{M}$ (Mo and Ballard, 2001). As the ratio of ATP/ADP is approximately 7 (e.g., 7.6 in Musch et al., 1980) and that of ADP/AMP again approximately 7 (e.g., 7.7 in Musch et al., 1980) and because adenine nucleotides are considerably more abundant than others, the $\gamma$-ATP signal composed of the sum of all nucleotides preferentially reflects ATP. For Pi, CSF concentrations of $1.39 \mathrm{mM}$ (Heipertz et al., 1979) were reported and the signal detected here corresponded to a total brain concentration of $0.74 \mathrm{mM}$. A direct cross-method validation of in vivo ${ }^{31} \mathrm{P}$-MRS versus ex vivo enzymatic assay of neutralized tissue homogenate supernatants found only $48 \%$ of available Pi detectable by ${ }^{31}$ P-MRS (Nioka et al., 1991).

Outcome parameters of this study were in the range reported by others. The PCr/ $\gamma$-ATP ratio of 1.6 found here agreed with the range 1.4-1.8 and specific ratio 1.5 reported by others (Lu et al., 2013; Novak et al., 2014). The concentrations of $2.45 \mathrm{mM} \mathrm{PCr}$ observed in the thalamus and of $3.22 \mathrm{mM}$ in the occipital region (averages of left and right at 9 A.M.) and of $2.95 \mathrm{mM}$ ATP and 0.8 $\mathrm{mM} \mathrm{Pi}$ in the thalamus are close to those of 3.1-3.5 mM PCr in gray matter, 2.9-3.3 $\mathrm{mM}$ in white matter, $2.40-2.54 \mathrm{mM}$ in the thalamus, $3.9-4.3 \mathrm{mM}$ in the occipital region, and of global 2.23.0 mM ATP and 0.9-1.3 mM Pi found by others (Buchli et al., 1994; Hetherington et al., 2001; Jensen et al., 2002; Du et al., 2007; Dworak et al., 2011; Ren et al., 2015). In our study, in the morning the PCr levels were $2.40 \mathrm{mM}$ in the left and $2.45 \mathrm{mM}$ in the right thalamus $(n=30)$ whereby the average of individual side differences amounted to $-1.9 \%$, the respective numbers were 2.35 $\mathrm{mM}$ left, $2.50 \mathrm{mM}$ right, and $-6.7 \%$ in the evening $(n=30)$. This was in agreement with results obtained by Jensen et al. (2002) of $2.40 \mathrm{mM}$ in the left and $2.54 \mathrm{mM}$ in the right thalamus amounting to $5.5 \%$ difference.

\section{Discussion}

Our study revealed a $7.0 \pm 0.8 \%$ diurnal decrease of PCr in the left thalamus between 9 A.M. and 5 P.M. A nap of 20 min restored PCr by $5.4 \%$. Pi showed inverse changes. Controls that did not nap did not show this reversal to baseline of $\mathrm{PCr}$ and $\mathrm{Pi}$. These highly significant data were corroborated by concing in vitro and in vivo evidence. Outcome measures, including an external calibration of absolute analyte concentrations, matched literature values, as we have shown.

\section{Cellular and neurochemical level}

Universally available energy in the cell is provided by ATP breakdown as follows (Eq. 6):

$$
A T P \underset{\text { ATPase-Synthase }}{\rightleftharpoons} \mathrm{ADP}+\mathrm{Pi}+\Delta \mathrm{E}
$$

PCr in turn acts as a reservoir for high-energy phosphate bonds to supply peak-load power and to capture ATP overflow. The transfer of this phosphate bond in both directions is catalyzed by the creatine kinase $(\mathrm{CK})$ in the brain by its mitochondrial isoforms CK-MT1a/b and the cytoplasmatic isoform CK-BB (compare Eq. 7). This opens up the established function of $\mathrm{PCr}$ as an intracellular energy shuttle from sites of production, such as mitochondria, to sites of consumption (Gabr et al., 2011), as shown in Equation 7:

$$
P C r+A D P \underset{\text { CK-MT1a/b }}{\rightleftharpoons} \mathrm{CK-B^{P }}
$$

CK can be regulated by phosphorylation, shifting equilibrium to the right (Lin et al., 2009). Consistent with the maintance of this equilibrium, ATP levels of our study underwent the same changes throughout all conditions as PCr, although the changes were not significant. The observed decrease of cytosolic $\mathrm{pH}$ in the afternoon might largely result from net hydrolysis of $\mathrm{PCr}$ to $\mathrm{Pi}$ and $\mathrm{Cr}$. Apparently cerebral storages of $\mathrm{Cr} / \mathrm{PCr}$ buffer are partially accessible by oral supplementation of Cr (Lyoo et al., 2003; Dworak et al., 2017).

\section{Daytime and thalamic energy consumption}

The physiological impact of our main finding is related to thalamic function. The thalamus serves as a gateway, relaying and modulating the information flow to and from mainly primary cortices. This "gate to the neocortex" is essential for the generation of consciousness and alertness (Steriade et al., 1993).

Beside the decrease of PCr in the left thalamus between 9 A.M. and 5 P.M., we found a substantial restoration of $\mathrm{PCr}$ values after a recreational nap of 20 and $40 \mathrm{~min}$ following the scan at 5 P.M. This finding is in line with the relatively short period needed for recreation even after longer times of wakefulness. We have recently shown that another neurochemical marker, $A_{1}$ adenosine receptors, which increase during $52 \mathrm{~h}$ of wakefulness, are restored to control levels during a recovery sleep episode of only $14 \mathrm{~h}$ (Elmenhorst et al., 2017). Considering the thalamus as a whole, many $\left[{ }^{18}\right.$ F]FDG-PET studies (Maquet et al., 1990, 1997; Braun et al., 1997) showed a decreased energy demand during sleep versus wakefulness, e.g., $-49 \%$ (Maquet et al., 1990) in slow-wave sleep (SWS). Similarly, our study in terms of PCr also showed a lower energy demand during the first period of sleep. Apparently not carrying weight to the macroscopic balance, higher neuronal firing rates (giving origin to spindle waves) were temporally registered within the first $30 \mathrm{~min}$ during the transition to lowfrequency SWS (Dijk et al., 1987) in subregions, such as the thalamic reticular nucleus.

\section{Aspects of lateralization}

Our findings indicate a lateralization of thalamic function, since the increase of $\mathrm{Pi} / \mathrm{PCr}$ was pronounced in the left thalamus. Lateral and specifically hemispheric specialization is a generally accepted concept of mammalian brains. It is well established for language and handedness as well as for other functions.

Numerous reports describe a side-specific subjection of the thalamus to sleep-associated changes and impacts on connectivity from mediating and propagating signals from sleep generators in forebrain, hypothamamic, and brainstem structures to the cerebral hemispheres in different species (Brown et al., 2012). Also, the "chemical neuroanatomy" shows a strong lateralization.

A prominent example is the norepinephrine system, which is highly relevant for arousal and sleep (Berridge, 2008) and has been shown to modulate thalamic activity (Devilbiss et al., 2006). Oke et al. (1978) showed that norepinephrine concentrations in the left thalamus are in most nuclei 1.5 to $>3$ times higher than in the right homolog. This "chemical lateralization" will necessarily translate into functional differences. Consistent with this are PET and fMRI studies reporting decreased thalamic activity during visual-vigilance tasks after sleep deprivation (Wu et al., 1991; Thomas et al., 2000), where the left deactivation exceeded the right by a factor of 1.1 and 1.5 , respectively. Also, circadian $\left[{ }^{18} \mathrm{~F}\right] \mathrm{FDG}$ studies detected a drop of uptake in the afternoon, which was accentuated in the right posterior temporal and occipital region (Buysse et al., 2004; Shannon et al., 2013). 
In line with these findings, use-dependent effects have been discussed as underlying hemispherically and regionally differential fatigue or sleep load (Borbély et al., 2016). As the subjects of this study performed scientific office work, which is particularly demanding on the left hemisphere, between the 9 A.M. and 5 P.M. session, lateralization may have been pronounced in this cohort. Temporal PCr levels were found lateralized independent of the condition. These results agree with results showing lower glucose metabolism in left temporal regions best matching the voxels R5C6 and R6C6 of this study versus right in the morning (by $-2.6,-3.9 \%$ ) and in the evening (by $-3.4,-3.6 \%$; Shannon et al., 2013). Macquet et al. (1990) observed $\sim 40 \%$ decrease of glucose consumption in SWS versus awake state, which was less pronounced in the left hemisphere by -3.4 and $-5.9 \%$ in middle and superior temporal regions. These findings could reflect permanent regional differences in the intensity and density of use contrasting with the daytime and sleep-related findings in the thalamus.

In muscle tissue, it is well established that during continued work energy (storage) compounds such as ATP, PCr, lactate, glucose, glucagone, and fats are consumed in that order and as long as stocks last. An overview of our results and those cited strongly suggests that in the brain the disposition on energy reserves does not occur synchronically but rather follows a spatiotemporal cascade as a function of regional wakefulness, activity, sleep, rest, and their intensity. In line with this idea, neuroimages of different activational parameters are not necessarily congruent. In perfectly resting tissue, full $\mathrm{PCr}$ stores and minimum $\left[{ }^{18} \mathrm{~F}\right] \mathrm{FDG}$ uptake can be expected. At the other end of the scale, beyond aerobic capacity-to limit cellular acidosis-glycolysis and thus $\left[{ }^{18} \mathrm{~F}\right] \mathrm{FDG}$ uptake may be downregulated despite deficient $\mathrm{PCr}$ reserves. This effect may apply to the more extreme situation of sleep deprivation. Consistent with this interpretation are the findings, by Wu et al. (1991), of a large decrease (-25\%) of $\mathrm{CMR}_{\mathrm{Glc}}$ in the left thalamus after sleep deprivation and the global decrease of PCr after sleep deprivation observed by Plante et al. (2014).

\section{Limitations}

First, the voxel defined as "thalamus" did not exactly match the anatomy of this brain structure. This is due to the rigid and predefined grid of relatively large voxels $(15.6 \mathrm{ml})$. As a consequence, a small posterior portion of the thalamus was omitted and adjacent structures, mostly internal capsule and CSF, were included. To estimate these effects, we segmented coregistered MPRAGE image datasets. Since we found no significant differences in the relative tissue portions between the left and right "thalamus" voxel, we can exclude this factor as an explanation for our main finding. Another factor is a lower statistical sensitivity in those voxels with a higher variability of included individual anatomy, such as in peripheral compared with central voxels. As the comparatively thin cortical layer is particularly sensitive to partial volume effects, cortical facets of the observed metabolic changes may have been underestimated.

Finally, we defined the nap status primarily by observational ratings. The physiological records of our subjects matched the reported scope, e.g., for drops in heart rate from wakefulness to sleep stages 1 and 2 as reported by Zemaityte et al. (1986) and Burgess et al. (1999), furthermore corroborated by the lack of awakening during the scan procedure and need for intense wake-up calls thereafter in all subjects. However, future studies could profit from additional EEG recordings and formal vigilance tests.

\section{Summary}

This study revealed a highly significant decrease of cytosolic $\mathrm{PCr}$ in the left thalamus between 9 A.M. and 5 P.M. accompanied by an inverse increase in Pi. The effect was largely reversible after a short recreational nap. A similar period of quiet waking did not result in the same kind of recovery of $\mathrm{Pi} / \mathrm{PCr}$ in controls. These findings support a daytime-related energy demand of the thalamus. Further, they provide evidence for a lateralized homeostatic regulation of the thalamus. Conversely to the dynamic lateralization of thalamic PCr, a constantly significant lateralization was observed in the temporal regions through all conditions.

As a methodological tradeoff, we showed that the ${ }^{31} \mathrm{P}$ relaxation behavior in the living brain can be mimicked by solutions of ATP in the presence of $\mathrm{Mg}$ and agarose alone and of $\mathrm{PCr}$ and $\mathrm{Pi}$ with additional Gd, all suitable for external calibration.

\section{References}

Agren H, Niklasson F (1988) Creatinine and creatine in CSF: indices of brain energy metabolism in depression. Short note. J Neural Transm 74:55-59. CrossRef Medline

Badzakova-Trajkov G, Häberling IS, Roberts RP, Corballis MC (2010) Cerebral asymmetries: complementary and independent processes. PloS One 5:e9682. CrossRef Medline

Benjamini Y, Hochberg Y (1995) Controlling the false discovery rate: a practical and powerful approach to multiple testing. J R Stat Soc B 57: $289-300$.

Berridge CW (2008) Noradrenergic modulation of arousal. Brain Res Rev 58:1-17. CrossRef Medline

Blenman R, Port J, Felmlee J (2006) In vivo measurement of T1 relaxation times of ${ }^{31} \mathrm{P}$ metabolites in human brain at 3T. Proc Intl Soc Mag Reson Med 14:3098.

Borbély AA, Daan S, Wirz-Justice A, Deboer T (2016) The two-process model of sleep regulation: A reapprisal. J Sleep Res 25:131-143. CrossRef Medline

Braun AR, Balkin TJ, Wesensten NJ, Carson RE, Varga M, Baldwin P, Selbie S, Belenky G, Herscovitch P (1997) Regional cerebral blood flow throughout the sleep-wake cycle. an $\mathrm{H}_{2}{ }^{15} \mathrm{O}$ PET study. Brain 120:1173-1197. CrossRef Medline

Brown RE, Basheer R, McKenna JT, Strecker RE, McCarley RW (2012) Control of sleep and wakefulness. Physiol Rev 92:1087-1187. CrossRef Medline

Buchli R, Duc CO, Martin E, Boesiger P (1994) Assessment of absolute metabolite concentrations in human tissue by ${ }^{31} \mathrm{P}$ MRS in vivo. Part I: Cerebrum, cerebellum, cerebral gray and white matter. Magn Reson Med 32:447-452. CrossRef Medline

Burgess HJ, Kleiman J, Trinder J (1999) Cardiac activity during sleep onset. Psychophysiology 36:298-306. CrossRef Medline

Buysse DJ, Nofzinger EA, Germain A, Meltzer CC, Wood A, Ombao H, Kupfer DJ, Moore RY (2004) Regional brain glucose metabolism during morning and evening wakefulness in humans. Sleep 27:1245-1254. CrossRef Medline

Casagrande M, Bertini M (2008) Night-time right hemisphere superiority and daytime left hemisphere superiority: a repatterning of laterality across wake-sleep-wake states. Biol Psychol 77:337-342. CrossRef Medline

Cohen SM, Burt CT (1977) ${ }^{31}$ P nuclear magnetic relaxation studies of phosphocreatine in intact muscle: determination of intracellular free magnesium. Proc Natl Acad Sci USA 74:4271-4275. CrossRef Medline

Crank J (1976) The mathematics of diffusion. 2nd ed. London: Oxford UP.

Devilbiss DM, Page ME, Waterhouse BD (2006) Locus ceruleus regulates sensory encoding by neurons and networks in waking animals. J Neurosci 26:9860-9872. CrossRef Medline

Dijk DJ, Beersma DG, Daan S (1987) EEG power density during nap sleep: reflection of an hourglass measuring the duration of prior wakefulness. J Biol Rhythms 2:207-219. CrossRef Medline

Du F, Zhu XH, Qiao H, Zhang X, Chen W (2007) Efficient in vivo 31P magnetization transfer approach for noninvasively determining multiple kinetic parameters and metabolic fluxes of ATP metabolism in the human brain. Magn Reson Med 57:103-114. CrossRef Medline

Dworak M, McCarley RW, Kim T, Kalinchuk AV, Basheer R (2010) Sleep 
and brain energy levels: ATP changes during sleep. J Neurosci 30:90079016. CrossRef Medline

Dworak M, McCarley RW, Kim T, Kalinchuk AV, Basheer R (2011) Replies to commentaries on ATP changes during sleep. Sleep 34:841-843. CrossRef Medline

Dworak M, Kim T, McCarley RW, Basheer R (2017) Creatine supplementation reduces sleep need and homeostatic sleep pressure in rats. J Sleep Res 26:377-385. CrossRef Medline

Elmenhorst D, Elmenhorst EM, Hennecke E, Kroll T, Matusch A, Aeschbach D, Bauer A (2017) Recovery sleep after extended wakefulness restores elevated A1 adenosine receptor availability in the human brain. Proc Natl Acad Sci USA 114:4243-4248. CrossRef Medline

Evelhoch JL, Ewy CS, Siegfried BA, Ackerman JJ, Rice DW, Briggs RW (1985) ${ }^{31} \mathrm{P}$ spin-lattice relaxation times and resonance linewidths of rat tissue in vivo: dependence upon the static magnetic field strength. Magn Reson Med 2:410-417. Medline

Gabr RE, El-Sharkawy AM, Schär M, Weiss RG, Bottomley PA (2011) Highenergy phosphate transfer in human muscle: diffusion of phosphocreatine. Am J Physiol Cell Physiol 301:C234-C241. CrossRef Medline

Gilboe DD, Kintner DB, Anderson ME, Fitzpatrick JH Jr (1998) NMRbased identification of intra- and extracellular compartments of the brain $P_{i}$ peak. J Neurochem 71:2542-2548. Medline

Harkness RA, Coade SB, Webster AD (1984) ATP, ADP and AMP in plasma from peripheral venous blood. Clin Chim Acta 143:91-98. CrossRef Medline

Heipertz R, Eickhoff K, Karstens KH (1979) Cerebrospinal fluid concentrations of magnesium and inorganic phosphate in epilepsy. J Neurol Sci 41:55-60. CrossRef Medline

Hetherington HP, Spencer DD, Vaughan JT, Pan JW (2001) Quantitative ${ }^{31} \mathrm{P}$ spectroscopic imaging of human brain at 4 tesla: assessment of gray and white matter differences of phosphocreatine and ATP. Magn Reson Med 45:46-52. CrossRef Medline

Holm S (1979) A simple sequentially rejective multiple test procedure. Scand J Stat 6:65-70.

Huang Y, Coman D, Herman P, Rao JU, Maritim S, Hyder F (2016) Towards longitudinal mapping of extracellular $\mathrm{pH}$ in gliomas. NMR Biomed 29:1364-1372. CrossRef Medline

Jensen JE, Drost DJ, Menson RS, Williamson PC (2002) In vivo brain ${ }^{31} \mathrm{P}$ MRS: measuring the phospholipid resonances at 4 tesla from small voxels. NMR Biomed 15:338-347. CrossRef Medline

Kan HE, Klomp DW, Wong CS, Boer VO, Webb AG, Luijten PR, Jeneson JA (2010) In vivo ${ }^{31} \mathrm{P}$ MRS detection of an alcaline inorganic phosphate pool with short T1 in human resting skeletal muscle. NMR Biomed 23: 995-1000. CrossRef Medline

Kato T, Shioiri T, Murashita J, Hamakawa H, Inubushi T, Takahashi S (1994) Phosphorus-31 magnetic resonance spectroscopy and ventricular enlargement in bipolar disorder. Psychiatry Res 55:41-50. CrossRef Medline

Lin G, Liu Y, MacLeod KM (2009) Regulation of muscle creatine kinase by phosphorylation in normal and diabetic hearts. Cell Mol Life Sci 66:135144. CrossRef Medline

Lu A, Atkinson IC, Zhou XJ, Thulborn KR (2013) PCr/ATP ratio mapping of the human head by simultaneously imaging of multiple spectral peaks with InterLeaved excitations and flexible twisted projection imaging readout trajectories (SIMPLE-TPI) at 9.4 tesla. Magn Reson Med 69:538-544. CrossRef Medline

Lu M, Zhu XH, Zhang Y, Chen W (2014a) Intracellular redox state revealed by in vivo ${ }^{31} \mathrm{P}$ MRS measurement of $\mathrm{NAD}^{+}$and NADH contents in brains. Magn Reson Med 71:1959-1972. CrossRef Medline

Lu M, Chen W, Zhu XH (2014b) Field dependance study of in vivo brain ${ }^{31} \mathrm{P}$ MRS up to 16.4 T. NMR Biomed 27:1135-1141. CrossRef Medline

Luby-Phelps K (2000) Cytoarchitecture and physical properties of cytoplasm: volume, viscosity, diffusion, intracellular surface area. Int Rev Cytol 192:189-221. Medline

Lüthi A (2014) Sleep spindles: where they come from, what they do. Neuroscientist 20:243-256. CrossRef Medline

Lyoo IK, Kong SW, Sung SM, Hirashima F, Parow A, Hennen J, Cohen BM, Renshaw PF (2003) Multinuclear magnetic resonance spectroscopy of high-energy phosphate metabolites in human brain following oral supplementation of creatine-monohydrate. Psychiatry Res: Neuroimaging 123:87-100. CrossRef Medline

Maquet P, Dive D, Salmon E, Sadzot B, Franco G, Poirrier R, von Frenckell R,
Franck G (1990) Cerebral glucose utilization during sleep-wake cycle in man determined by positron emission tomography and $\left[{ }^{18} \mathrm{~F}\right] 2$-fluoro-2deoxy-D-glucose method. Brain Res 513:136-143. CrossRef Medline

Maquet P, Degueldre C, Delfiore G, Aerts J, Péters JM, Luxen A, Franck G (1997) Functional neuroanatomy of human slow-wave sleep. J Neurosci 17:2807-2812. CrossRef Medline

Marek T, Fafrowicz M, Golonka K, Mojsa-Kaja J, Oginska H, Tucholska K, Urbanik A, Beldzik E, Domagalik A (2010) Diurnal patterns of activity of the orienting and executive attention neural networks in subjects performing a stroop-like task: a functional magnetic imaging study. Chronobiol Int 27:945-958. CrossRef Medline

Marshall I, Higinbotham J, Bruce S, Freise A (1997) Use of Voigt lineshape for quantification of in vivo ${ }^{1} \mathrm{H}$ spectra. Magn Reson Med 37:651-657. CrossRef Medline

Mathur-De Vré R, Maerschalk C, Delporte C (1990) Spin-lattice relaxation times and nuclear overhauser enhancement effect for ${ }^{31} \mathrm{P}$ metabolites in model solutions at two frequencies: implications for in vivo spectroscopy. Magn Reson Imaging 8:691-698. CrossRef Medline

McCormick DA (2002) Cortical and subcortical generators of normal and abnormal rhythmicity. Int Rev Neurobiol 49:99-114. CrossRef Medline

Mo FM, Ballard HJ (2001) The effect of systemic hypoxia on interstitial and blood adenosine, AMP, ADP and ATP in dog skeletal muscle. J Physiol 536:593-603. CrossRef Medline

Musch TI, Pelligrino A, Dempsey JA (1980) Effects of prolonged $\mathrm{N}_{2} \mathrm{O}$ and barbiturate anesthesia on brain metabolism and $\mathrm{pH}$ in the dog. Respir Physiol 39:121-131. CrossRef Medline

National Institute of Standards and Technology (1996) Data plot reference manual. pp. 66-67. Gaithersburg, MD: U.S. Department of Commerce. Available at: an2/homepagehtm.

Nioka S, Chance B, Lockard SB, Dobson GP (1991) Quantitation of high energy phosphate compounds and metabolic significance in the developing dog brain. Neurol Res 13:33-38. CrossRef Medline

Nir Y, Staba R, Andrillon T, Vyazovskiy W, Cirelli C, Fried I, Tononi G (2011) regional slow waves and spindles in human sleep. Neuron 70:153-169. CrossRef Medline

Novak J, Wilson M, MacPherson L, Arvanitis TN, Davies NP, Peet AC (2014) Clinical protocols for ${ }^{31} \mathrm{P}$ MRS of the brain and their use in evaluating optic pathway gliomas in children. Eur J Radiol 83:e106-112. CrossRef Medline

Oke A, Keller R, Mefford I, Adams RN (1978) Lateralization of norepinephrine in human thalamus. Science 200:1411-1413. CrossRef Medline

Oldfield RC (1971) The assessment and analysis of handedness: the Edinburgh inventory. Neuropsychologia 9:97-113. CrossRef Medline

Petroff OA, Prichard JW, Behar KL, Rothman DL, Alger JR, Shulman R (1985) Cerebral intracellular $\mathrm{pH}$ by ${ }^{31} \mathrm{P}$ nuclear magnetic resonance spectroscopy. Neurology 35:1681-1688. CrossRef Medline

Plante DT, Trksak GH, Jensen JE, Penetar DM, Ravichandran C, Riedner BA, Tartarini WL, Tartarini WL, Dorsey CM, Renshaw PF, Lukas SE, Harper DG (2014) Gray matter-specific changes in brain bioenergetics after acute sleep deprivation: a ${ }^{31} \mathrm{P}$ magnetic resonance spectroscopy study at 4 tesla. Sleep 37:1919-1927. CrossRef Medline

Porkka-Heiskanen T, Kalinchuk AV (2011) Adenosine, energy metabolism and sleep homeostasis. Sleep Med Rev 15:123-135. CrossRef Medline

Rao R, Ennis K, Lubach GR, Lock EF, Georgieff MK, Coe CL (2018) Metabolomic analysis of CSF indicates brain metabolic impairment precedes hematological indices of anemia in the iron-deficient infant monkey. Nutr Neurosci 21:40-48. CrossRef Medline

Ren J, Sherry AD, Malloy CR (2015) ${ }^{31}$ P-MRS of healthy human brain: ATP synthesis, metabolite concentrations, $\mathrm{pH}$ and $\mathrm{T}_{1}$ relaxation times. NMR Biomed 28:1455-1462. CrossRef Medline

Rial R, González J, Gené L, Akaârir M, Esteban S, Gamundí A, Barceló P, Nicolau C (2013) Asymmetric sleep in apneic human patients. Am J Physiol Regul Integr Comp Physiol 304:R232-R237. CrossRef Medline

Shannon BJ, Dosenbach RA, Su Y, Vlassenko AG, Larson-Prior LJ, Nolan TS, Snyder AZ, Raichle ME (2013) Morning-evening variation in human brain metabolism and memory circuits. J Neurophysiol 109:1444-1456. CrossRef Medline

Steriade M, McCormick DA, Sejnowski TJ (1993) Thalamocortical oscillations in the sleeping and aroused brain. Science 262:679-685. CrossRef Medline 
Thomas M, Sing H, Belenky G, Holcomb H, Mayberg H, Dannals R, Wagner H, Thorne D, Popp K, Rowland L, Welsh A, Balwinski S, Redmond D (2000) Neural basis of alertness and cognitive performance impairments during sleepiness 1: effects of $24 \mathrm{~h}$ of sleep deprivation on waking human regional brain activity. J Sleep Res 9:335-352. CrossRef Medline

Trksak GH, Bracken BK, Jensen JE, Plante DT, Penetar DM, Tartarini WL, Maywalt MA, Dorsey CM, Renshaw PF, Lukas SE (2013) Effects of sleep deprivation on brain bioenergetics, sleep and cognitive performance in cocaine-dependent individuals. ScientificWorldJournal 2013:947879. CrossRef Medline

Urrila AS, Hakkarainen A, Heikkinen S, Huhdankoski O, Kuusi T, Stenberg D, Häkkinen AM, Porkka-Heiskanen T, Lundbom N (2006) Preliminary findings of proton magnetic resonance spectroscopy in occipital cortex during sleep. Psychiatry Res 147:41-46. CrossRef Medline

Wallimann T, Wyss M, Brdiczka D, Nicolay K, Eppenberger HM (1992) Intracellular compartmentation, structure and function of creatine kinase isoenzymes in tissues with high and fluctuating energy demands: the 'phosphocreatine circuit' for cellular energy homeostasis. Biochem J 281: 21-40. CrossRef Medline

Wilson M, Reynolds G, Kauppinen RA, Arvanitis TN, Peet AC (2011) A constrained least-squares approach to the automated quantitation of in vivo ${ }^{1} \mathrm{H}$ magnetic resonance spectroscopy data. Magn Reson Med 65:112. CrossRef Medline

Wu JC, Gillin JC, Buchsbaum MS, Hershey T, Hazlett E, Sicotte N, Bunney WE Jr (1991) The effect of sleep deprivation on cerebral glucose metabolic rate in normal humans assessed with positron emission tomography. Sleep 14:155-162. Medline

Wu JC, Gillin JC, Buchsbaum MS, Chen P, Keator DB, Khosla Wu N, Darnall LA, Fallon JH, Bunney WE (2006) Frontal lobe metabolic decreases with sleep deprivation not totally reversed by recovery sleep. Neuropsychopharmacology 31:2783-2792. CrossRef Medline

Zemaityte D, Varoneckas G, Plauska K, Kaukenas J (1986) Components of the heart rhythm power spectrum in wakefulness and individual sleep stages. Int J Psychophysiol 4:129-141. CrossRef Medline 